\title{
The impact of a firm's make, pseudo-make, or buy strategy on product performance
}

\author{
Jin-Kyu Park ${ }^{\mathrm{a}}$, Young K. Ro ${ }^{\mathrm{b}, *}$ \\ a College of Business Administration, Chung-Ang University, 221 Dongjak-gu, Seoul 156-756, South Korea \\ b College of Business, University of Michigan - Dearborn, 19000 Hubbard Dr., Dearborn, MI 48126, United States
}

\section{A R T I C L E I N F O}

\section{Article history:}

Received 12 October 2009

Received in revised form 9 August 2010

Accepted 17 August 2010

Available online 24 August 2010

Keywords:

Modular/integral product architecture

Make/pseudo-make/buy sourcing strategy

U.S. bicycle industry

\begin{abstract}
A B S T R A C T
The bulk of the product architecture and make-buy choice literature deals with product architecture changes from integral to modular form. This development is often associated with a firm's tendency to change from a make to a buy strategy. However, a few studies investigate the change of product architecture in the reverse direction - from modular to integral form - and the subsequent change in the firm sourcing decision from a buy to a make strategy. These studies hold to the presumption that a firm following a make strategy will outperform firms following a buy strategy in dealing with integral product architectures. Based on the knowledge-based view, we argue for the viability of a sourcing strategy between the pure make and buy strategies - a pseudo-make strategy. We also argue that as product architecture changes from a modular to integral form, firms adopting this pseudo-make strategy are likely to show better product performance than firms following a pure make or buy strategy due to the relative knowledge advantages of the pseudo-make strategy in dealing with the integral product architecture. We examine the impact of the make/pseudo-make/buy strategies on product performance in the U.S. bicycle derailleur and freewheel market from 1980 to 1992 and provide theoretical and managerial implications of our results. Our findings highlight an important distinction between the pseudo-make and make-buy strategies that has not previously been fully appreciated in the extant literature, and as a result increases our understanding of why some firms do not switch strategies from a buy to a make strategy when product architecture changes from modular to integral form as previously expected.
\end{abstract}

(C) 2011 Published by Elsevier B.V.

\section{Introduction}

\subsection{Motivation}

There has been growing interest in the relationship between product architecture (PA) and a firm's make or buy (M/B) strategy over the last several years (Fine, 1998; Baldwin and Clark, 2000; Christensen et al., 2002). During this time, a substantial PA and M/B literature body has developed that indicates that many products are becoming increasingly modular over time, and that this development is often associated with a firm's tendency to change from a make to a buy strategy (Sturgeon, 2002). A classic example of this phenomenon is seen in the personal computer industry (Fine, 1998; Baldwin and Clark, 2000). Before IBM opened up the PA of its personal computer, the architectural design of the personal computer was integral in form and firms tended to pursue a make strategy over a buy strategy. This was the state of the product and industry in the personal computer market for a few years - until Apple came

\footnotetext{
* Corresponding author.

E-mail addresses: jinbest@gmail.com (J.-K. Park), yro@umich.edu (Y.K. Ro).
}

along. In response to Apple's challenge, IBM opened its modular PA up to potential suppliers and many specialized firms entered the market by adopting IBM's modular PA. Even IBM's rivals used the modular PA in their PC clones. Shortly thereafter, IBM's modular PA became the standard in the market. Once there existed many capable specialized component firms in the PC market, the 'buy' strategy proved to be more efficient than the 'make' strategy in dealing with the modular PA. The more firms adopted the modular PA, the greater the chance for specialized component firms to thrive. Over time, these self-reinforcing complementarities between the firms' proclivities to use outside suppliers and the prevalence of suppliers producing components within the framework of the modular PA led more firms to change from a make to a buy strategy.

Interestingly, the majority of relevant empirical research follows the direction demonstrated in the personal computer industry example - a PA change towards higher degrees of modularity and the impact of this PA change on firms' M/B choices (Sanchez and Mahoney, 1996; Garud et al., 2002; Jacobides and Winter, 2005). Although there exist industries that demonstrate a change of PA from modular to integral form triggered by radical (or architectural) innovations such as the disk drive (Christensen et al., 2002), 
PC (Fine, 1998), notebook computer (Hoetker, 2006), Swiss watch (Jacobides and Winter, 2005), cell phone and HDTV industries, much of the extant literature reflects an evolution of PA and firms' $\mathrm{M} / \mathrm{B}$ decisions in one predominant direction - that of the PA changing from integral to modular form and firms' decisions to change from a make to a buy strategy. Given that much of the previous scholarly work has dealt with primarily one evolutionary direction, this study's interest lies in the opposite direction.

\subsection{Shortcomings in the literature}

A few earlier studies suggest that when the architecture of a product changes from modular to integral form via radical or architectural innovation, firms are likely to pursue a make strategy over a buy one (Fine, 1998; Christensen et al., 2002; Jacobides and Winter, 2005). Given that most of the existing research resides in one evolutionary perspective, these small number of works are believed to be meaningful. However, this study finds one limitation of these earlier pieces. Most of them are based on anecdotal analysis, presuming that when dealing with integral PAs, a firm following a make strategy performs better than a firm following a buy strategy. With this presumption, some scholars jump to the conclusion that firms are likely to change from a buy to a make strategy as the PA changes from modular to integral form. However, testing this presumption empirically tends to be overlooked in earlier research. If somehow firms following a buy strategy exhibit superior (or similar) performance to firms with a make strategy, then the firms pursuing a buy strategy may not be strongly motivated to pursue a make strategy in the face of a modular-to-integral PA change.

If true, this expectation would differ from the conclusion that earlier studies of the make-buy strategy have suggested (Sanchez and Mahoney, 1996; Fine, 1998; Christensen et al., 2002). Therefore, without theoretically and empirically validating the impact of a firm's make-buy decision on performance, simply investigating the relationship between PA and firm behavior regarding a firm's make-buy choice will not provide clear prescriptive or normative managerial implications. Given the lack of theoretical and empirical validation of the aforementioned presumption, the purpose of this study is to validate this presumption and ask the research question, "As PA changes from modular to integral form, are firms with a buy strategy able to outperform firms with a make strategy in dealing with the new integral PA?"

\subsection{Purpose of study}

Previous studies seem to ignore the possibility that a firm's knowledge and capability prior to a change of PA from modular to integral form could affect a firm's performance when dealing with a new integral PA (Nelson and Winter, 1982). When the dominant PA in a particular industry is modular, firms often pursue a buy strategy (e.g. via outsourcing, alliance building) (Fine, 1998). However, firms pursuing a buy strategy may readily possess different knowledge capabilities. Some firms may outsource the entire design and manufacturing functions to outside suppliers while others may outsource only the manufacturing function, keeping the design capability inhouse. This latter type of sourcing strategy, where the knowledge capability is kept in-house (e.g. Brusoni et al., 2001), is described as a 'pseudo-make strategy' and is essentially a type of hybrid buy strategy with the knowledge advantages akin to the make strategy combined with the functional outsourcing of the buy strategy. Firms practicing a pseudo-make strategy may be reluctant to outsource any knowledge-relevant design and development work to external suppliers, assigning only the function of component production to them. Given the possibility that a pseudo-make strategy does exist, distinctive from either the make or buy strategy, our overarching argument is that there is a strategy in between the pure make and buy strategies - herewith called a pseudo-make strategy - and that as PA changes from modular to integral form, firms adopting this pseudo-make strategy are likely to show better product performance than firms following a pure make or buy strategy due to the relative advantages of the pseudo-make strategy over the make or buy strategies in knowledge search, sharing, and integration required in dealing successfully with the new integral PA. Accordingly, the purpose of this study is to examine the impact of the make/pseudo-make/buy (M/PM/B) strategies on product performance in the U.S. bicycle derailleur/freewheel market from 1980 to 1992 . By doing so, this study provides valuable contributions to the extant literature. The traditional dichotomous make and buy sourcing strategies have been established in the transaction cost economics (TCE) literature for quite some time. However, with this $\mathrm{M} / \mathrm{PM} / \mathrm{B}$ categorization, our study finds that in dealing with integral PAs, even derailleur firms engaged in outsourcing activities can offer product performance at a similar level to those of firms with a make strategy, provided that commensurate knowledge on the outsourced components remains in-house (i.e. the pseudo-make strategy). This suggests that the presumption ${ }^{2}$ of existing works may not always be true. We therefore highlight an important distinction between the pseudo-make and buy strategies that has not previously been fully appreciated in the extant literature, and as a result, increases our understanding of why some firms do not switch strategies from a buy to a make strategy when PA changes from modular to integral form as previously expected.

For the development of our overarching arguments, we draw on the KBV (knowledge-based view) and firm/knowledge boundary literature within the framework of the PA and M/B choice literature (Fine, 1998; Christensen et al., 2002). To explain why we are using the KBV and firm/knowledge boundary literature, it should be noted that this research specifically focuses on product performance. When a PA is standardized and modular in form, rather than competing for improved product performance, firms will often compete over price/cost reductions or by conveniently customizing product features and functions (Christensen et al., 2002). However, when a PA changes to integral form via radical or architectural innovation and subsequently tilts the market towards the new integral PA, firms are more likely to compete by providing improved product performance in order to win competitive advantage (Christensen et al., 2002). Therefore, looking into the impact of a firm's strategy on product performance is meaningful to this study. Given that our major interest is on the impact of the M/PM/B decision on product performance in dealing with integral PAs, we need a literature base that sheds light on the relationship between PA change and firm/knowledge boundary decisions and its effect on product performance. Earlier research within the KBV literature emphasized the importance of knowledge to create and sustain competitive advantage(Wernerfelt, 1984; Barney, 1991). It explained how organizational governance choice - in particular, the advantages of a make strategy - influences knowledge exchange and protection (Conner and Prahalad, 1996; Grant, 1996; Kogut and Zander, 1996). Nickerson and Zenger (2004) theoretically proposed a discriminating alignment between problem complexity (i.e. the degree of interdependence among knowledge sets) and alternative organizational arrangements (markets, authority-based hierarchy, and consensus-based hierarchy) that vary according to their abilities to mitigate knowledge formation hazards and to their impact on product performance and solution search (Afuah, 2001; Macher, 2006). The firm/knowledge boundary literature also provides a clear reason for the existence of a pseudo-make strategy, suggesting that such a strategy provides unique firm advantages distinct from

\footnotetext{
2 The presumption that firms utilizing a make strategy are likely to exhibit superior performance to firms utilizing a buy strategy.
} 
the advantages of the pure make or buy strategies (Brusoni et al., 2001; Dosi et al., 2003). The less-than-perfect overlap between the knowledge and firm boundary has been corroborated via in-depth industry case studies based on both qualitative and quantitative evidence (Brusoni, 2005; Brusoni and Prencipe, 2006). We therefore believe that both the KBV and firm/knowledge boundary literature are directly relevant to the interest of this study and provide a rich theoretical backdrop for the development of our arguments.

\section{Theory and hypothesis development}

\subsection{Theoretical background}

Product architecture (PA) is dynamic (Baldwin and Clark, 2000; Shibata et al., 2005). As discussed earlier, a substantial literature stream suggests that many products are becoming more modular over time and this development is often associated with a firm's tendency to pursue a buy strategy over a make strategy. During the early stage of an industry, firms are unfamiliar with customer needs and technology mechanisms, leading to misalignments between desired product performance and customer needs. Firms may need to experiment with new product designs and technologies to satisfy customers, lending themselves to generate PAs integral in form. However, once a dominant design emerges and the industry matures, firm competition revolves around refinements of existing components within the dominant architecture. Once many firms adopt the dominant design, the PA becomes modular and standardized. Component linkages and associated knowledge is disseminated and firms become more efficient by focusing on specific components. In this environment, specialized component firms can easily enter the market and firms may tend to use external suppliers as the number of capable suppliers increases. The availability of such suppliers is likely to tempt firms to use a buy strategy and purchase components through outsourcing or alliance arrangements.

In contrast to the PA evolution explained above, radical (or architectural) innovations often trigger the change of PA from modular to integral form (Jacobides and Winter, 2005; Shibata et al., 2005). While much of the extant literature shares the notion of increasing product modularity and the accompanying tendency of firms to pursue a buy strategy, a few meaningful studies provide the possibility of an opposite-direction evolution of PA and M/B choice (Fine, 1998; Christensen et al., 2002; Fixson and Park, 2008). This body of opposite-directional studies suggest that as PA changes from modular to integral form, firms may prefer a make strategy over a buy strategy with the presumption that firms adopting a make strategy will outperform firms that adopt a buy strategy.

Given the lack of research validating the aforementioned presumption, the theoretical and empirical validation of this presumption is of particular interest to this study. Specifically, in the situation where PA changes from modular to integral form via radical or architectural innovation, this study looks into the impact of the $\mathrm{M} / \mathrm{PM} / \mathrm{B}$ choice on product performance in dealing with a new integral PA. Differing from earlier studies, this study categorizes a firm's make or buy strategy into three separate strategies: make, pseudo-make, and buy. Our main arguments revolve around the relative advantages offered by a pseudo-make strategy in the search, sharing, and integration of knowledge over a make or a buy strategy.

Also, as mentioned earlier, this study focuses on product performance. When the dominant PA in an industry is modular and standardized, firms tend to compete on price/cost reductions (Christensen et al., 2002), but the change of PA from modular to integral form leads firms to compete on the basis of product performance (Fine, 1998; Christensen et al., 2002; Jacobides and Winter,
2005). This was the case in the U.S. bicycle derailleur/freewheel market both before and after index shifting technology was introduced. Index shifting technology, an architectural innovation, changed the PA of the bicycle driving-train set from modular to integral form. It altered the basis of firm competition and enacted tremendous product performance advantages over the traditional technology. Index shifting technology was in such demand by customers that bicycles without the technology did not sell well on the market. Thus, bicycle makers rushed to adopt the technology mainly to improve their product (shifting) performance (Fixson and Park, 2008). Given the change in the basis of competition, product performance became a key factor in firm success. It is therefore very meaningful to explore the impact of a firm's M/PM/B choice on product performance in the face of a modular-to-integral PA change.

\subsection{Make strategy vs. buy strategy}

As PA changes from modular to integral form, a make strategy is more likely to provide the knowledge advantages required in dealing with the new integral PA than a buy strategy and firms with a make strategy are more likely to show better product performance than firms with a buy strategy. Modular PAs, which permit components to be developed and produced separately and to be used interchangeably (Baldwin and Clark, 2000), do not require extensive systemic knowledge that encompasses multiple knowledge sets regarding product components and architectures. They also do not necessitate a high degree of integration of manufacturing systems since these types of PAs demand little coordination among various component designs and manufacturing tasks. In dealing with a modular PA, the buy strategy provides many advantages to firms. A firm can realize cost savings and product diversity advantages when pursuing the buy strategy. A buy strategy allows individual firms and suppliers to develop and exploit their specialized expertise (Hammond and Miller, 1985). Component interchangeability increases competitive market pressures, providing incentives for suppliers to increase product quality (Alston and Gillespie, 1989), improve product features, and decrease time to market (Christensen and Rosenbloom, 1995; Christensen, 1997). Although pursuing a make strategy has its own merits in terms of promoting coordination among interdependent tasks and facilitating knowledge sharing and transfer (Demsetz, 1988; Monteverde, 1995; Kogut and Zander, 1996), these advantageous features are less needed when dealing with modular PAs since product configurations remain relatively unchanged and components are standardized and interchangeable. Therefore, firms using a buy strategy can thrive in markets driven by modular PAs to a greater degree than firms using a make strategy (Christensen and Rosenbloom, 1995; Baldwin and Clark, 2000).

However, when PA changes from modular to integral form, an alternative situation occurs. In the integral PA context, the systemic interconnectivity of components results in a situation where a change in one component necessitates changes to other components in the system. This requires firms to extensively evaluate potential consequences of various solution approaches (Gavetti and Levinthal, 2000) to improve performance of the end product. The significant connectivity between product components within integral PAs entails intensive communication and knowledge sharing between the focal firms and suppliers if certain components are outsourced. The increased interdependence between various component designs and manufacturing tasks leads to the situation in which suppliers' components may need to be customized to fit those made by the buying firms (Williamson, 1975, 1985). This design interdependency leads to the situation in which significant component coordination is necessary to facilitate the understanding of complexity of integral PAs. Basically, integral PAs present 
relatively high-complexity problems for firms since they require extensive knowledge sharing and exchange when making component changes to optimize product performance.

Due to the need for extensive knowledge sharing and integration, a buy strategy yields many disadvantages for firms in dealing with an integral PA. It limits firms' administrative controls and communication channels and constrains firms from embracing adaptive, sequential, and interrelated changes needed to cope with the high component interdependence of integral PAs. A buy strategy is inefficient due to its weak support of knowledge sharing and limited protection against knowledge appropriation. For integral PAs, firms that facilitate the free sharing of information without risk of appropriation or accumulation and where disputes between firms can be monitored and resolved in a timely matter are required instead (Teece, 1992). A make strategy is comparatively advantaged in dealing with an integral PA as its firm-specific languages, communication codes, and information channels, combined with their low-powered incentives and dispute resolution mechanisms, encourage knowledge sharing and promote coordination (Monteverde, 1995; Grant, 1996; Kogut and Zander, 1996). The formation of research and development goals and the definition of research agendas are also easier under a make strategy. These repeatedly occur due to the interdependence of integral PAs implying that a make strategy better facilitates the dissemination of new knowledge through the formation of firm-specific languages and communication codes (Nickerson and Zenger, 2004).

Thus, there are comparative performance advantages of the make strategy over the buy strategy in dealing with an integral PA. A make strategy is better able to manage the extensive knowledge interdependencies through superior knowledge sharing and integration. Due to the relative advantages of the make strategy over the buy strategy in dealing with high-complexity problems, firms adopting a make strategy may show superior product performance to those that do not when dealing with an integral PA. The above arguments lead to the following hypothesis.

Hypothesis 1. When dealing with an integral PA, firms pursuing a make strategy are more likely to exhibit better product performance than firms pursuing a buy strategy.

\subsection{Psuedo-make strategy vs. buy strategy}

In today's hypercompetitive business environment, most companies cannot design and manufacture their product without the help of external organizations. Since cutting-edge knowledge necessary for radical (architectural) innovation tends to be widely dispersed across different firms, innovation in some highly dynamic industries appears only possible if a firm reaches beyond its boundaries. This observation has led some scholars to suggest that the locus of innovation might be found in a network of alliances, especially in high-technology industries (Powell et al., 1996; Rothaermel and Deeds, 2004). The increasing trend of knowledge specialization for the design and production of products creates difficulties for firms that depend purely on in-house knowledge (Brusoni et al., 2001). For desirable performance of innovative products, it is therefore critical for firms to gain and integrate external knowledge.

A pseudo-make strategy is believed to have comparative knowledge advantages over a buy strategy. A firm will often gain knowledge by buying outsourced components from a highly skilled supplier. Such learning opportunities will be most productive when the firm also has strong relevant expertise because its internal skills create an absorptive capacity that enables knowledge transfer (Cohen and Levinthal, 1990). The pseudo-make strategy allows a firm to maintain awareness of external technologies and new knowledge created outside of the firm (Cohen and Levinthal, 1990).
It also allows for the firm to absorb new knowledge and apply it quickly to design and development projects, enabling the creation of newer products that incorporate modern technologies. Also, the pseudo-make strategy yields strategic flexibility to the firm since it allows a firm to integrate design and production activities or to outsource them. Toyota is one example of a firm utilizing a successful pseudo-make strategy. Given that the interdependence of electronics and mechanical parts in automobiles is increasing, Toyota chose to source electrical components both internally and from Denso (its largest external supplier) in order to better understand the technology and learn indirectly about competitors (Fine, 1998). In fact, Toyota outsources the majority of the components of many of its vehicles, yet maintains internal competency in the components it outsources (Ro et al., 2007). This allows Toyota to learn with and from its suppliers without ever transferring all core knowledge and responsibility in any area to suppliers. Basically, the pseudomake strategy leaves room for new knowledge to be built upon the existing internal knowledge stock of a firm and allows for product and design improvement to satisfy customer demands. As a result, the knowledge generation and integration opportunities existing under a pseudo-make strategy can improve product performance, and the mixing of various knowledge stocks increases a firm's design and production capabilities (Brown and Eisenhardt, 1997) and helps a firm maintain awareness of external technologies and new knowledge. However, under a buy strategy, any new knowledge gained from working with an external firm cannot be added to any existing internal knowledge stock of a firm since the pure buy strategy precludes such commensurate internal know-how.

As PA changes from modular to integral form triggered by radical innovations, the sharing and integration of new external and existing internal knowledge is critical. When considering the case of a modular PA, since the end system can be decomposed into separate independent modules, extensive communication and coordination between the firm and its supplier is not necessary in outsourcing situations. But in the case of an integral PA, components are tightly coupled, necessitating the need for coordinated design and production processes to create optimal linkages between components to ensure optimum product or system performance. When considering the high degree of component connectivity existing within integral PAs, optimal integration of a firm's existing knowledge and supplier's external knowledge is key for desirable product performance. In fact, integral PAs have been described as being able to deliver higher functional performance than their modular architecture counterpart (Ulrich, 1995), implying that superior product performance requires the design, manufacture, and integration of external and internal knowledge of components. With a pseudo-make strategy, a firm is better able to identify appropriate project partners and shun low-quality partners (Akerlof, 1970; Brusoni et al., 2001) since they better understand the technological linkages between components and retain design competence inhouse. This enables a firm to better assess a partner's skills, judge its willingness to perform, evaluate its ability to accept guidance, and provide feedback through technological transactions. With a pseudo-make strategy, since existing knowledge provides a foundation for absorptive capacity (Cohen and Levinthal, 1990), the outsourcing firm is able to communicate technical requirements to its supplier partner on a regular basis to ensure and provide instruction that the outsourced components are manufactured to specifications. Since a firm with a pseudo-make strategy can more critically evaluate a supplier partner's capability level and its readiness to perform required tasks, the firm is better able to integrate any external/internal knowledge necessary to learn and understand intertwined tasks involved in component development for integral PAs (Mayer and Salomon, 2006). In contrast, in a pure buy strategy situation, this tight coupling of components required for superior product performance would be difficult to emulate 
since both the design and manufacturing knowledge would be housed within the supplier partner, putting the outsourcing firm at a knowledge coordination and integration disadvantage.

Given its relative strengths, firms engaging in a pseudo-make strategy are more likely to be faced with opportunities to learn valuable technical knowledge and integrate this learning in-house. As a result, the pseudo-make strategy should provide better opportunities to gain and share knowledge than the pure buy strategy. As explained by Takeishi (2002), while "the actual tasks of designing and manufacturing components could be outsourced, the relevant knowledge should be retained internally to gain higher quality component design." (p. 331). Ultimately, the pseudo-make strategy should have a positive impact on a firm's product performance. This line of reasoning yields the following hypothesis:

Hypothesis 2. When dealing with an integral product architecture, firms pursuing a pseudo-make strategy are more likely to exhibit better product performance than firms pursuing a buy strategy.

\subsection{Make strategy vs. pseudo-make strategy}

A pseudo-make strategy has comparative advantages over a make strategy with regards to knowledge search and integration. A firm that engages in a pseudo-make strategy has access to a broader stock of relevant knowledge (Powell, Koput, and SmithDoerr, 1996) than a firm engaging purely in a make strategy. As mentioned in the development of Hypothesis 2, up-to-date knowledge needed for successful innovation tends to be spread out over several different firms, and as a result, a firm desiring to pursue innovative product development is greatly advantaged if the firm extends its knowledge search beyond its boundaries (Rothaermel and Deeds, 2004). The pseudo-make strategy allows a firm to access external knowledge via strategic partnerships with potential suppliers and integrates this knowledge into the in-house design activities. This access to external knowledge coupled with the firm's internal knowledge and capability enlarges the absorptive capacity of the firm (Cohen and Levinthal, 1990) and prevents the firm from becoming dependent on internal technical knowledge stocks (Lei et al., 1996). It allows the firm to innovate and develop a larger set of high quality products in order to gain competitive advantage in the marketplace. It is true that under market uncertainty, a firm pursuing a make strategy can grow and improve its product offerings by integrating valuable technical knowledge. But firms under a make strategy would lose access to information and knowledge from suppliers. And in the case of unforeseen innovations in the business landscape, current capabilities of a firm can be rendered obsolete (Henderson and Clark, 1990; Leonard-Barton, 1992) and updating these capabilities can be cost prohibitive in a make strategy situation. Finally, a make strategy reduces a firm's manufacturing flexibility, lengthening design time and the ability to introduce new products (Harrigan, 1984). Given the comparative advantages of the pseudo-make strategy over the make strategy, a firm with a pseudo-make strategy will be in a better position to develop relationships with external sources in order to gain access to new technical knowledge developed outside of the firm's boundaries (Cohen and Levinthal, 1990).

Due to the relative knowledge advantages of the pseudo-make strategy over the make strategy, firms with a pseudo-make strategy are likely to show better product performance than firms with a make strategy in dealing with integral PAs. As mentioned previously, the change of PA from modular to integral form often requires new technological knowledge outside the firm boundary to be integrated with the firm's internal knowledge. Both the make and pseudo-make strategies require a certain degree of managerial and task coordination to integrate design and production processes. But it is the pseudo-make strategy that allows room for relevant external knowledge to be added to the equation. Under the pseudo-make strategy, firms can enrich product performance by internalizing current valuable technological knowledge. At the same time, they can develop and maintain external sourcing relationships to gain access to new technical knowledge developed beyond the firms' boundaries (Powell et al., 1996; Rothaermel et al., 2006). In contrast, the pure make strategy provides a much lower degree of strategic freedom for product development and innovation. The pure make strategy reduces a firm's ability to access new knowledge that could prove useful in designing and producing successful products. It would cause the firm to behave more like a closed system and prevent it from strategically responding to dynamic contingencies in the external environment. As a result, the make strategy inadvertently leaves greater room for technological obsolescence, lack of information sharing, and strategic inflexibility (Harrigan, 1984; Rothaermel et al., 2006) than the pseudo-make strategy in the long run.

Based on the knowledge advantages provided by the pseudomake strategy and the potential dangers offered by a pure make strategy, we conclude that the pseudo-make strategy is likely to result in superior product performance. This is not unlike Rothaermel et al.'s (2006) argument that managing an intelligent hybrid of the make and buy strategies via a form of taper integration appears to improve a firm's product success and competitive performance. Ultimately, this line of reasoning yields the following hypothesis.

Hypothesis 3. When dealing with an integral product architecture, firms pursuing a pseudo-make strategy are more likely to exhibit better product performance than firms pursuing a make strategy.

\section{Method}

\subsection{U.S. bicycle derailleur and freewheel market}

The above hypotheses are tested by observing the U.S. derailleur and freewheel market from 1980 to 1992 . The derailleur and freewheel are two important components in the bicycle driving-train set. The derailleur is a mechanism that moves the bicycle chain from freewheel sprocket to freewheel sprocket during gear shifting on a multi-speed bicycle. This study's interest lies in the consequences of firms' M/PM/B decisions regarding freewheel components ${ }^{3}$ on product performance.

Prior to 1985, when index shifting technology (an architectural innovation) came to market, the architecture of the driving-train set was standardized throughout the industry. A derailleur made by one firm could be interchangeable with a freewheel made by another (Bicycling, March, 1987, pp. 38-42). Then in 1985, index shifting technology was introduced to the market and enabled the chain to move precisely from freewheel to freewheel during shifting, reducing rattling sounds as bicycle riders searched for chain alignment (Bicycling, March, 1987, pp. 38-42). The new index shifting technology was distinctively different from the normal driving-train set. First, it required the use of indexed components, even though they looked very similar to conventional components.

\footnotetext{
3 The derailleur was a much more expensive and complicated component than the freewheel. While the freewheel was composed of at most 10 sub-components, the derailleur consisted of anywhere from around 30 to 60 sub-components. Most bicycle driving-train set firms made their derailleurs in-house and considered whether they should make in-house or purchase externally the freewheel components. Since the derailleur was both complicated and expensive, it was extremely rare for freewheel or other component companies to make the derailleur in-house or to even purchase a derailleur company via M\&A.
} 
Second, proper index shifting technology required firms to understand new PA knowledge regarding the derailleur and freewheel. The linkage between the derailleur and freewheel - called the chain gap - became extremely important in the new indexed shifting technology and was not significant for the more traditional and conventional driving-train sets (Fixson and Park, 2008). Understanding how to optimize the size of this chain gap was a critical part in providing desirable derailleur shifting performance. This optimal chain gap was contingent on the features of the derailleur and freewheel. It was so sensitive that even a minor change in the derailleur could easily require a change in the freewheel design. Through much trialand-error experimentation, it was possible to create an optimized chain gap for optimal shifting performance. Once index shifting technology came into the picture, the PA changed from modular to integral form and the shifting performance was affected by not only the derailleur and freewheel component themselves but also the optimized chain gap linkage between the derailleur and the freewheel. Given the fluctuation of PA caused by the index shifting technology, the U.S. bicycle derailleur and freewheel market from 1980 to 1992 sets itself apart as an appropriate setting for testing the study's hypotheses.

\subsection{Sample and data collection}

In this study, the key dependent variables relate to the derailleur shifting performance. Firms can pursue both modular and integral PAs at the same time. While a firm may pursue a make strategy for one derailleur/freewheel model, the same firm could also pursue an outsourcing strategy for another model. Therefore, characterizing a whole firm as engaging in an integral or modular PA, or characterizing a whole firm as pursuing a make, pseudo-make, or buy strategy, could lead to an under/overestimation of test results (Baldwin, 2007). To deal with this problem, this study uses individual derailleur/freewheel sets for each 'new' bicycle driving-train model as a unit of analysis. More specifically, this study looks into derailleur firms' M/PM/B strategies regarding freewheels for each new bicycle driving-train model. By taking this approach, the unit of analysis becomes a singular bicycle derailleur/freewheel set for each bicycle model. This prevents the under/overestimation regarding a firm's propensity to pursue a M/PM/B strategy. ${ }^{4}$

This study's primary data sources for the new bicycle drivingtrain set models were garnered from Bicycling's and Bicycle Annual's performance databases. Both trade magazines tested the drivingtrain sets of various bicycles every year between 1980 and 1992 . For each new model produced by 26 different derailleur firms, the database provided each bicycle's derailleur performance such as 'derailleur movement' and 'number of miss-shiftings'. The data sources also specified model titles, component names, and manufacturers of freewheels. The data included the performance numbers of a total of 492 new bicycle driving-train sets.

In addition, all other information concerning a firm's M/PM/B decision, PA change, and other independent/instrumental variables presented in this study is primarily based on Bicycling's Super Spec Database (SSD) and Bicycle Annual's Buyer's Guide (BG). However, SSD and BG did not specify the information mentioned above between 1990 and 1992. But former technical editors of Bicycling and Bicycle Annual provided additional data sets that were previ-

\footnotetext{
${ }^{4}$ As a point of illustration, suppose a bicycle maker introduces several new products in a given year with $80 \%$ of those products made entirely in-house and the remaining $20 \%$ of those products made with outsourced component sets. It would be inappropriate to evaluate the bicycle maker's make-buy strategy by merely viewing the characteristics of one individual product. We accommodate for this by looking specifically at each derailleur firm's M/PM/B decision regarding the freewheel component for each single driving-train model, leaving the unit of analysis at the individual product level.
}

ously used to create SSD and BG. Based on this additional data, complete information was obtained for the period between 1980 and 1992. Other literary archives such as the Proceedings of the International Cycling History Conference, the book 'Dancing Chain', and Sutherland's Handbook for Bicycle Mechanics (6th edition) were also very helpful in understanding market and technological changes.

Based on the archival data analyses, this study constructed the history of each firm, portraying a complete picture of firms' $\mathrm{M} / \mathrm{PM} / \mathrm{B}$ decisions, PA changes, and all other relevant independent and instrumental variables. The history of each firm, technological changes, and other variables were then reviewed by the industry experts interviewed to assess accuracy and any necessary corrections. ${ }^{5}$ Through the data collection and analysis process, this study compiled an unusually thorough data set.

\subsection{Measures}

\subsubsection{Dependent variables}

Number of missed shiftings (SMOOTH) and derailleur movement gap (DMG). The key dependent variable was product performance. For product performance, we used two criteria recorded by the Bicycling and Bicycle Annual trade magazines. The first one was the number of missed shiftings (SMOOTH) during the test period. This criterion was based on how many times riders missed gear shiftings during a certain trial duration. Since missed shiftings could happen due to causes other than problems with the derailleur and freewheel, Bicycling magazine had special test tools which could control for missed shiftings stemming from other components, reporting only the number of missed shiftings from the combination of the derailleur and freewheel components. Special test machines repeatedly and randomly changed chains from freewheel to freewheel within a certain time period. With these test machines, Bicycling and Bicycle Annual tested each bicycle driving-train set for $3 \mathrm{~h}$, recording SMOOTH. The other performance criterion dealt with the derailleur movement gap (DMG). This is the lever movement travel distance required for derailleur re-centering. ${ }^{6}$ From a technical standpoint, the rear derailleur has to track the cogs very closely so that the chain is forced onto the next gear, requiring minimal play in the rear derailleur pivots and parallelogram. Without the proper DMG minimizing the lever travel distance, bicycle riders can easily hear noisy friction between the freewheel and chain. Simply put, minimizing any movement in the derailleur is fundamental for crisp and proper shifting. Each derailleur was run through all 16 shifts. After each shift, the tester adjusted the shift lever until the jockey pulley was exactly centered under the freewheel sprocket. The tester then measured how much lever movement was required for this re-centering, which was recorded as the DMG. The shorter the $D M G$, the better the shifting performance.

\subsubsection{Independent variables}

Make, pseudo-make, buy. There are two major independent variables in our study's design. One is the firm's decision regarding the

\footnotetext{
5 In addition to the archival data, several interviews were conducted with industry experts mainly to review the history of the variables suggested in this study The informants interviewed included current and former employees of 15 firms selected for this case study including CEOs, technical directors, marketing directors, mid-level project managers, and engineers. Current and former technical editors of bicycling-related magazines served as informants external to the firms and were also interviewed.

${ }^{6}$ Our second dependent variable, DMG, should not be confused with the chain gap. While the chain gap was simply the distance between the derailleur and freewheel $D M G$ was the lever movement (travel) distance required for derailleur re-centering. Proper $D M G$ required the use of indexed components and required firms to acquire the optimal chain gap. The DMG was not so much an issue of design but depended on whether firms used indexed components and how well they achieved the optimal chain gap.
} 
M/PM/B decision. Bicycling's Super Spec Database (SSD) and Bicycle Annual's Buyer's Guide (BG) provided information regarding firms' decisions on the M/PM/B strategies for each driving-train set model. Based on this data, for each individual firm's decision, we identified how a transaction to procure the freewheel was organized in each new driving-train set. We classified the firm's decision as 'make' if a firm made the freewheel in-house, as 'pseudo-make' if a firm designed the freewheel in-house but outsourced the manufacturing of the freewheel to a supplier partner, and as 'buy' if a firm completely outsourced the freewheel to a partner. It should be noted that a firm's make-buy decision can be considered an orderly categorical variable and therefore is coded as zero for a buy decision, one for a pseudo-make decision, and two for a make decision.

Product architecture (PA). The second independent variable is $P A$. As explained earlier, while a traditional conventional drivingtrain set did not require extensive interaction of components, a driving-train with the newer index shifting technology needed high coordination between components. Accordingly, if a driving-train component set did not include index shifting technology, it would entail a modular PA. If a driving-train component set included index shifting technology, it would entail an integral architecture between the derailleur and freewheel. Hence, if the PA is integral, $P A$ is coded as one, and if the PA is modular, PA is coded as zero.

\subsubsection{Control variables}

Derailleur age. The more experience a firm has in producing a derailleur, the more familiar it becomes with the design and production of the derailleur component and the sourcing arrangements involved in dealing with the freewheel component from freewheel suppliers. Derailleur Age was measured as the number of years that a firm had produced the derailleur component.

Derailleur complexity. Of all the bicycle driving-train components, the derailleur was the most critical for shifting and the most complicated to the extent that it was sometimes compared to the Intel chip within a PC. The complexity of the derailleur could directly influence shifting performance. The most complex derailleurs included three key features - a two spring-loaded pivot, a slant parallelogram, and a Shimano-style cage geometry (Berto, 2005). These features became part of more complicated derailleur designs as the component evolved over time. Thus, the derailleur design complexity became directly influenced by the following:

(1) Whether it included two spring-loaded pivots. Before 1985, most derailleurs used only one spring-loaded pivot. The two spring-loaded pivots were later created to better improve derailleur movement.

(2) Whether it included a slant parallelogram. Similar to the two spring-loaded pivot, the slant parallelogram replaced the traditional simple parallelogram design. Adding the slant parallelogram feature improved derailleur movement.

(3) Whether it included a Shimano-style cage geometry. In a similar evolution to the other two features, the Shimano-style cage geometry replaced the older, traditional Campagnolo ${ }^{7}$-style cage geometry in the late 1980s. The Shimano-style cage geometry enhanced derailleur movement but was more complicated in its design.

We categorized derailleur complexity as '0', if it included none of the three. ' 1 ', if it included only one of three. ' 2 ', if it included two of three, and ' 3 ', if it included all three features.

\footnotetext{
7 A leading Italian bicycle component manufacturer. Until 1985, when Shimano came to dominate the market with index shifting technology, Campagnolo was the leading bicycle component manufacturer.
}

Derailleur/freewheel sales. Derailleur/freewheel sets that inherently sold in greater quantity may have better shifting performance than derailleur/freewheel sets that did not sell well. We captured Derailleur/Freewheel Sales by using the number of derailleur/freewheel sets sold every year, calculated in the Super Spec Database.

$M / P M / B$ duration. This variable is defined as the number of years that a firm has pursued its current $\mathrm{M} / \mathrm{PM} / \mathrm{B}$ strategy. The longer the time period a firm follows a make strategy, the greater the chance of the firm having better capability to deal with the make strategy, potentially affecting product performance. Similarly, if a firm keeps a pseudo-make strategy for a long time, they may acquire or develop unique capabilities for knowledge search and integration. And if a firm keeps a buy strategy for a long time, the firm may acquire certain capabilities to efficiently deal with its suppliers (Gulati, 1995) which could affect product performance (Dyer, 1997). By capturing the effects of firm-supplier relationships, in-house knowledge, and in-house production experience levels (Leiblein et al., 2002), this control variable could potentially capture the impact of changing $\mathrm{M} / \mathrm{PM} / \mathrm{B}$ strategies by a firm on product performance.

Firm size. Firm size may confound the effects of firm boundary on a firm's competitive advantage (D'Aveni and Ravenscraft, 1994) and may also provide firms with advantages in managing R\&D efforts or innovative activities (Panzar and Willig, 1981; Cohen and Klepper, 1996). Larger firms may have greater access to complementary technologies and downstream capabilities (e.g. marketing, finance) that make R\&D more productive (Cohen and Klepper, 1996). This study captures size by using market share as a proxy and was calculated in the Super Spec Database.

Firm innovation capabilities. A firm's technological innovation capabilities regarding the derailleur could affect product performance (Hoetker, 2005, 2006). Therefore, firm innovation capabilities needed to be considered and were measured by the number of patents concerning the derailleur per year.

Firm age. Firm age may influence both a firm's performance and its choice of a particular governance form (Barnett, 1990; Amburgey et al., 1993). Firm age is measured as the number of years that a firm made the derailleur component. With regards to firm age, older more experienced firms would probably exhibit superior product performance.

Firm Dummies and Year Dummies. Our model also included two sets of dummy variables. First, Firm Dummies for the 26 firms in our sample were used to capture any unmeasured heterogeneity across panels. Second, Year Dummies from 1980 to 1992 controlled for unobserved factors that vary over time, capturing any overall changes in impact on product performance due to new technology introduction, legal issues, and the like.

\subsubsection{Instrumental variables}

As will be explained later in more detail, we used a twostage switching regression model (Hamilton and Nickerson, 2003) based on Heckman's method (1979) to analyze the data. This method incorporates the analysis of instrumental variables and is a regression-based statistical design model that captures several decision factors (i.e. make, pseudo-make, or buy decisions) affecting product performance. The two-stage switching regression model without instrumental variables often leads to very unstable and unreliable estimates of parameters. When employing the two-stage switching regression model, scholars have voiced two cautions. First, variables associated with legal issues, government policy, or industry environmental changes that 'all' firms, whether characterized by a make or a buy strategy, must face need to be considered (Hamilton and Nickerson, 2003). Second, these variables should affect the firm governance mode choice but should not directly affect product performance. As a result, they would be 
captured in the first-stage estimation and not enter directly into the second-stage estimation. This study includes two instrumental variables believed to satisfy these two concerns.

Number of freewheel suppliers. This measure accounts for the effect that shifts in bargaining power due to the number of available suppliers will have on firms' make or buy decisions (Williamson, 1985; Pisano, 1990). This measure was obtained by counting the number of freewheel firms that supplied production of freewheels.

Market demand uncertainty. Around the year 1990, demand for MTBs (mountain bicycles) significantly increased (Fixson and Park, 2008). The sales volatility for bicycle models could have a direct impact on whether firms utilize outsourcing arrangements (Dess and Beard, 1984). Following Levy (1985) and Leiblein et al. (2002), the log of firm bicycle sales was regressed on a time trend. The variance of error term was used as a measure of Market Demand Uncertainty.

\subsubsection{Analysis}

Empirically testing the effect of $\mathrm{M} / \mathrm{PM} / \mathrm{B}$ decisions on product performance is not a simple problem due to endogeneity (selfselection) issues (Hamilton and Nickerson, 2003). Firms rarely approach the make-buy decision as a mutually exclusive event (Baldwin, 2007). The decision is often biased towards one direction due to the past propensity of a firm to choose one particular course of action. For example, firms choosing a make strategy may have particular production capabilities that are unobservable in specific statistical models. These capabilities could make the firms' make strategy a highly profitable and attractive choice. Contrastingly, if firms following a buy strategy decide to follow a make strategy, they would initially be less profitable than firms that originally chose a make strategy. As a result, a regression of performance on makebuy strategies that does not allow for endogeneity may not clearly answer the effect of M/PM/B choices on product performance, and normative implications drawn from the regression may be incorrect (Leiblein et al., 2002). The use of interaction terms also leads to biased estimations (Mayer and Nickerson, 2005), since the interaction terms are highly likely to be correlated with the original terms (Greene, 2003). The now-accepted approach of correction for such treatment effects is a two-stage switching regression model (Heckman, 1979) permitting an integrative model that simultaneously captures firms' M/PM/B decisions as well as the observed and unobserved factors affecting product performance (for a more detailed explanation, see Hamilton and Nickerson, 2003).

The first of the two stages in Heckman's (1979) regression model deals with firms' sourcing strategy choices in the face of modularto-integral PA change. Here, the goal is to obtain the inverse Mills ratio via a probit model which will then be used in the second stage. In the first stage, a probit model is estimated to specify the relationship between PA and a firm's decision on the M/PM/B strategies, including the two instrumental variables. Here is the first-stage selection model:

$$
\begin{aligned}
& \text { Strategy }_{i j}=\alpha_{0}+\alpha_{1} \times \text { Product Architecture }_{i j} \\
& +\alpha_{2} \times \text { Derailleur Age }_{i j}+\alpha_{3} \times \text { Derailleur Complexity }_{i j} \\
& +\alpha_{4} \times \text { Derailleur/Freewheel Sales }{ }_{i j} \\
& +\alpha_{5} \times M / P M / \text { B Duration }_{i j}+\alpha_{6} \times \text { Firm Size }_{i j} \\
& +\alpha_{7} \times \text { Firm Innovation Capabilities }{ }_{i j} \\
& +\alpha_{8} \times \text { Firm Age }_{i j}+\alpha_{9} \times \text { No. of Freewheel Suppliers }{ }_{i j} \\
& +\alpha_{10} \times \text { Market Demand Uncertainty }+\varepsilon_{i j}
\end{aligned}
$$

where $i$ represents the derailleur/freewheel sets, $j$ the firm, $\varepsilon_{i j}$ the random error term and Strategy $y_{i j}$ the index of an ordered probit estimation. With respect to actual strategy choices, Strategy $y_{i j}=0$ if
Strategy $y_{i j} \leq \mu_{1}$, Strateg $y_{i j}=1$ if $\mu_{1} \leq$ Strateg $_{i j} \leq \mu_{2}$, and Strategy $y_{i j}=2$ if Strategy $y_{i j}>\mu_{2}$, where $\mu_{1}$ and $\mu_{2}$ are referred to as break points in the ordered probit.

We then calculated the inverse Mills ratio, which was for correcting endogenous self-correction. In the second stage, we estimated our product performance model (2), which is of major interest in this study. The performance model (2) did include the inverse Mills ratio terms as regressors along with all the variables that jointly influenced performance and governance mode choices in order to obtain unbiased estimates of coefficients for all the variables. However, performance model (2) excluded the two instrumental variables - No. of Freewheel Suppliers and Market Demand Uncertainty, both of which were used in the first stage. The inverse Mills ratio corrects for sample selection bias that may arise from self-selection of the M/PM/B choice (Heckman, 1979). Without such a correlation, our coefficient estimates could be biased by unobservable factors affecting both the $\mathrm{M} / \mathrm{PM} / \mathrm{B}$ choice and product performance.

In the second stage, which is of main interest to this study, we pooled the yearly product- and firm-level data and estimated a single model in which dependent variables were defined as SMOOTH and DMG; both product-level measures. While the dependent variables were at the product level, the independent variables included not only product-level, but also firm-level variables. Pooling repeated observations on the same firms would therefore likely violate the assumptions of observation independence, resulting in temporal autocorrelation of the model's residuals and rendering OLS estimates inefficient (Klein and Kozlowski, 2000). To compensate for non-independence, we concluded our analysis using a firm-specific fixed-effects model. The final model took the form:

$$
\begin{aligned}
\text { Product Performance }_{i j k}= & \beta_{0}+\beta_{1} \times \text { Product Architecture }_{i j k} \\
& +\beta_{2} \times \text { Derailleur Age }_{i j k} \\
& +\beta_{3} \times \text { Derailleur Complexity }_{i j k} \\
& +\beta_{4} \times \text { Derailleur/Freewheel Sales }_{i j k} \\
& +\beta_{5} \times \text { M/PM/B Duration } n_{i j k} \\
& +\beta_{6} \times \text { Firm Size }_{i j k} \\
& +\beta_{7} \times \text { Firm Innovation Capabilities }_{i j k} \\
& +\beta_{8} \times \text { Firm Age }_{i j k} \\
& +\beta_{9} \times \text { Firm Dummies } \\
& +\beta_{10} \times \text { Year Dummies } \\
& +\beta_{11} \times \text { Mills_Ratio }_{k}+\varepsilon_{i j k}
\end{aligned}
$$

where $i$ represents the derailleur/freewheel sets, $j$ the firm, $k$ the make, pseudo-make, or buy decision, Mills_Ratio the inverse Mills ratio for organizing decision $k$ and $\varepsilon_{i j k}$ a random error term. While PA, Derailleur Age, Derailleur Complexity, Derailleur/Freewheel Sales, and $M / P M / B$ Duration are product-level variables, Firm Size, Firm Innovation Capabilities, and Firm Age, are firm-level variables.

In order to generate the final product performance model Eq. (2), several steps were incurred. We first carried out a standard OLS regression test (see both Model 1s in Tables 4 and 5). We presented cluster estimates of standard error at the firm level to account for the firm-level effects shown in both Model 1s of Tables 4 and 5 (to be explained in Section 4). Note, as well, the extremely large differences between the conventional OLS standard errors and the robust (cluster) corrected values. The three- or four-fold differences in magnitude of standard deviation strongly suggested that there were latent effects, at least at the firm level. At this point, it remained to be considered which approach, fixed or random effects, was preferred. Secondly, we then tested a generalized Hausman 
(1978) specification test for fixed vs. random effects, and the fixedeffect model prevailed. ${ }^{8}$ We initially included $\varepsilon_{i j}$, which was the product and firm interaction error term, and $V_{j}$, which was the firm error term. But since the fixed-effects model survived, we dropped the $V_{j}$ term (Raudenbush and Bryk, 2001). The results also indicated that the firm-specific residual was likely to differ between firms yet remain constant for multiple observations from the same firm (Bowen and Wiersema, 1999; Greene, 2003). In order to embody firm-level effects more specifically, not only did we add firm size, firm innovation capabilities, and firm age, but we also added firm dummies, which controlled for several constant firm-level factors. We also added time dummies to account for some events that may take place within a particular year (both Model 2s and Model 3s in Tables 4 and 5). For example, some firms could have implemented a new major quality improvement program in a certain year which could lead to increases in product performance. We finally tested our product performance model (2), which included the inverse Mills ratio stemming from the first-stage regression (1), in the two-stage switching regression model (see both Model $4 \mathrm{~s}$ in Tables 4 and 5).

Since SMOOTH was a discrete counting variable and DMG was a simple continuous variable, we needed two different statistical procedures. For SMOOTH, the dependent variable exhibited overdispersion - with the variance significantly exceeding the mean - and thus a negative binomial regression was preferred over the more common Poisson model (Hausman et al., 1984). However, the assumption with a negative binomial model is that even counts are independent, which was not the case in our study. In order to deal with non-independence, as mentioned before, we used fixed-effect negative binomial models via the XTNBREG procedure in STATA. Regarding DMG, we ran a fixed-effect LSDV (least square dummy variables) model using the XTREG procedure in STATA.

\section{Results}

Table 1 displays the summary statistics and correlation coefficients for the variables in our study. Table 2 provides the summary statistics for all variables categorized by the firms' M/PM/B strategies. As shown, no correlation among the theoretical variables was deemed large enough to pose estimation problems, although the correlations among several of the control variables were occasionally high with only two exceeding 0.6 . Such levels of multicollinearity among explanatory variables could result in less precise parameter estimates (i.e. larger standard error) for the correlated variables but should not bias parameter estimates (Greene, 2003; Kennedy, 2003).

In order to account for any endogeneity issues, we employed a two-stage switching regression model. Accordingly, we first describe the estimation results of the first-stage selection model based on our Eq. (1). We then explain the results of the second-stage performance model based on Eq. (2).

\footnotetext{
8 For SMOOTH, a generalized Hausman (1978) specification test for fixed vs. random effects produced a chi-squared value of $2,536.04$. The critical value was 15.507. And for DMG, a chi-squared value was 3881.45 and the critical value was 15.507 . These would imply that the fixed effects model would be the preferred specification. Our initial model included $\varepsilon_{i j}$, which was the product and firm interaction error term, and $V_{j}$, which was the firm error term: Product Performance $_{i j}=\beta_{0}+\beta_{1} \times$ Product Architecture A $_{i j}+\beta_{2} \times$ Derailleur Age $_{i j}+\beta_{3} \times$ Derailleur Complexity $_{i j}+\beta_{4} \times$ Derailleur/Freewheel Sales $_{i j}+\beta_{5} \times M / P M / B$ Duration $_{i j}+\beta_{6} \times$ Firm Size $_{i j}+\beta_{7} \times$ Firm Innovation Capabilities $i j+\beta_{8} \times$ Firm Age $_{i j}+V_{j}+\varepsilon_{i j}$. However, when we calculated the Hausman statistic using the two-level hierarchical estimates (i.e. including the $\varepsilon_{i j}$ and $V_{j}$ terms), the statistics for SMOOTH and DMG remained larger than the critical value. As it was that the fixed effects model survived, we dropped the $V_{j}$ term.
}

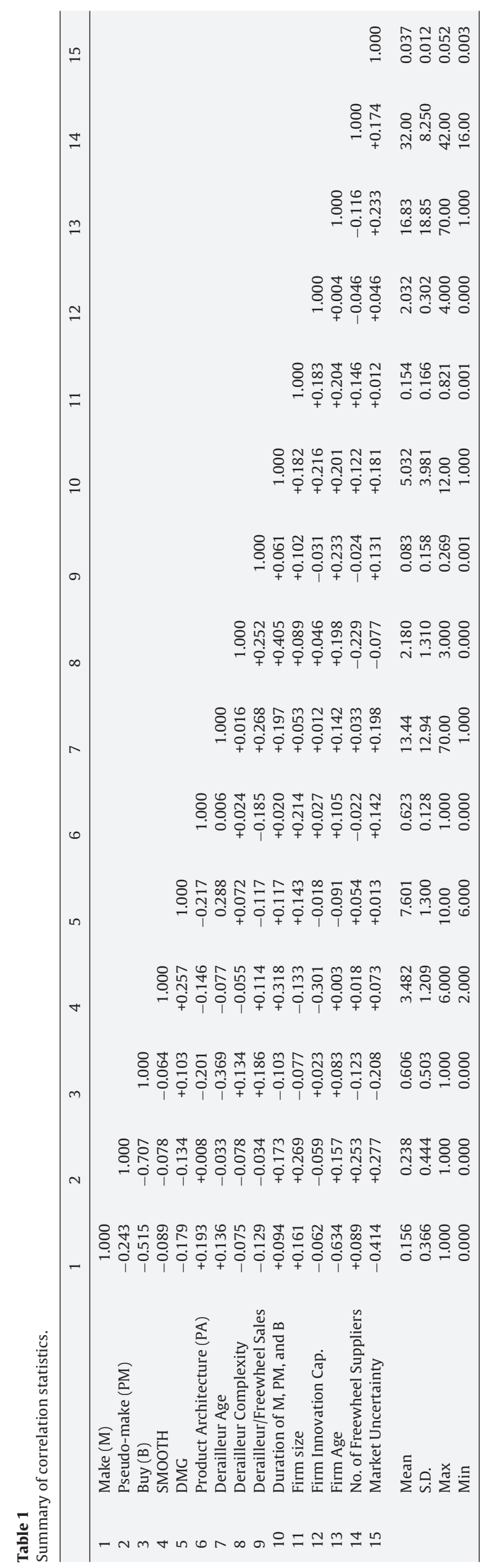


Table 2

Summary statistics for buy, pseudo-make, and make strategies.

\begin{tabular}{|c|c|c|c|c|c|c|c|c|c|c|c|c|}
\hline & \multicolumn{4}{|c|}{ Buy $(n=280)$} & \multicolumn{4}{|c|}{ Pseudo-make $(n=110)$} & \multicolumn{4}{|c|}{ Make $(n=102)$} \\
\hline & Mean & S.D. & Max & Min & Mean & S.D. & Max & Min & Mean & S.D. & Max & Min \\
\hline SMOоTH & 3.829 & 1.183 & 6.000 & 2.000 & 3.316 & 1.082 & 5.000 & 2.000 & 3.304 & 0.825 & 5.000 & 3.000 \\
\hline DMZ & 8.649 & 1.285 & 10.00 & 7.000 & 7.429 & 1.361 & 9.000 & 6.000 & 7.337 & 1.119 & 9.000 & 7.000 \\
\hline Product Architecture (PA) & 0.583 & 0.124 & 1.000 & 0.000 & 0.627 & 0.275 & 1.000 & 0.000 & 0.758 & 0.175 & 1.000 & 0.000 \\
\hline Derailleur Age & 13.82 & 11.82 & 70.00 & 1.000 & 14.91 & 12.38 & 70.00 & 1.000 & 8.430 & 12.92 & 70.00 & 1.000 \\
\hline Derailleur Complexity & 1.520 & 0.141 & 3.000 & 0.000 & 2.563 & 1.510 & 3.000 & 0.000 & 2.664 & 1.460 & 3.000 & 0.000 \\
\hline Derailleur/Freewheel Sales & 0.021 & 0.001 & 0.032 & 0.000 & 0.108 & 0.015 & 0.201 & 0.001 & 0.121 & 0.104 & 0.269 & 0.001 \\
\hline Duration of Buy, PM, and Make & 4.889 & 3.240 & 12.00 & 1.000 & 7.183 & 2.577 & 12.00 & 1.000 & 6.458 & 1.587 & 12.00 & 1.000 \\
\hline Firm size & 0.111 & 0.178 & 0.314 & 0.001 & 0.175 & 0.202 & 0.581 & 0.001 & 0.264 & 0.411 & 0.821 & 0.001 \\
\hline Firm Innovation Cap. & 2.562 & 0.123 & 4.000 & 2.000 & 0.678 & 0.102 & 2.000 & 0.000 & 2.298 & 1.052 & 4.000 & 2.000 \\
\hline Firm Age & 15.45 & 15.92 & 70.00 & 1.000 & 18.72 & 6.921 & 70.00 & 1.000 & 19.93 & 17.67 & 70.00 & 1.000 \\
\hline No. of Freewheel Suppliers & 38.00 & 8.862 & 42.00 & 16.00 & 35.00 & 6.541 & 42.00 & 16.00 & 28.00 & 5.281 & 42.00 & 16.00 \\
\hline Market Uncertainty & 0.023 & 0.003 & 0.032 & 0.012 & 0.033 & 0.011 & 0.045 & 0.008 & 0.042 & 0.018 & 0.063 & 0.002 \\
\hline
\end{tabular}

\subsection{First-stage selection results}

The first-stage selection model relates to the firms' decisions on the $\mathrm{M} / \mathrm{PM} / \mathrm{B}$ strategies in dealing with integral PAs. Model 1 in Table 3 is a baseline model and does not include the PA variable. Model 2 includes the $P A$ variable. Model 3 incorporates the two instrumental variables - Number of Freewheel Suppliers and Market Demand Uncertainty. While Model 2 is not an improvement in fit over Model $1\left(\chi^{2}(1)=2.15, p>0.1\right)$, Model 3 represents an improvement in fit over Model $1\left(\chi^{2}(3)=78.29, p<0.01\right)$.

The results regarding the coefficients of $P A$ in Models 2 and 3 also proved to be positively significant $(p<0.01)$. This would indicate that the firms in our study exhibited a strong tendency to pursue a make strategy over a buy or pseudo-make strategy when dealing with an integral PA; an anticipated outcome based on the literature (Williamson, 1985; Fine, 1998; Christensen et al., 2002). We also tested for the combination of the buy and pseudo-make strategies and found that the significance of the test results turned out

Table 3

First-stage estimation results.

\begin{tabular}{|c|c|c|c|}
\hline Make, pseudo-make, buy choice & Model 1 & Model 2 & Model 3 \\
\hline PA (Product Architecture) & & $\begin{array}{l}+0.621^{* * *} \\
(0.208)\end{array}$ & $\begin{array}{l}+0.682^{* * *} \\
(0.213)\end{array}$ \\
\hline Derailleur Age & $\begin{array}{l}-0.161 \\
(0.212)\end{array}$ & $\begin{array}{l}+0.290 \\
(0.193)\end{array}$ & $\begin{array}{l}+0.272 \\
(0.171)\end{array}$ \\
\hline Derailleur Complexity & $\begin{array}{l}+0.292^{* * *} \\
(0.061)\end{array}$ & $\begin{array}{l}+0.398^{* *} \\
(0.167)\end{array}$ & $\begin{array}{l}+0.383^{* *} \\
(0.173)\end{array}$ \\
\hline Derailleur/Freewheel Sales & $\begin{array}{l}+0.409 \\
(0.365)\end{array}$ & $\begin{array}{l}+0.632 \\
(0.536)\end{array}$ & $\begin{array}{l}+0.668 \\
(0.524)\end{array}$ \\
\hline Duration of make, PM, and buy & $\begin{array}{l}+0.545 \\
(0.353)\end{array}$ & $\begin{array}{l}-3.310 \\
(5.631)\end{array}$ & $\begin{array}{l}+2.694 \\
(5.382)\end{array}$ \\
\hline Firm size & $\begin{array}{l}2.964^{* * *} \\
(0.755)\end{array}$ & $\begin{array}{l}+1.510^{*} \\
(0.669)\end{array}$ & $\begin{array}{l}+3.537^{* *} \\
(1.414)\end{array}$ \\
\hline Firm Innovation Cap. & $\begin{array}{l}+1.159^{* * * *} \\
(0.079)\end{array}$ & $\begin{array}{l}+0.118^{* * *} \\
(0.008)\end{array}$ & $\begin{array}{l}+0.102^{* * *} \\
(0.014)\end{array}$ \\
\hline Firm Age & $\begin{array}{l}-0.033 \\
(0.117)\end{array}$ & $\begin{array}{l}-0.113^{* * *} \\
(0.011)\end{array}$ & $\begin{array}{l}-0.014^{* *} \\
(0.007)\end{array}$ \\
\hline No. of Freewheel Suppliers & & & $\begin{array}{l}-0.162^{* * *} \\
(0.009)\end{array}$ \\
\hline Market Demand Uncertainty & & & $\begin{array}{l}+0.205^{* *} \\
(0.101)\end{array}$ \\
\hline Constant & $\begin{array}{l}-3.430^{* *} \\
(1.559)\end{array}$ & $\begin{array}{l}-3.899^{* *} \\
(1.854)\end{array}$ & $\begin{array}{l}-3.185^{* * *} \\
(0.968)\end{array}$ \\
\hline$N$ & 492 & 492 & 492 \\
\hline $\log L$ & -258.24 & -256.81 & -198.27 \\
\hline Adjusted $R^{2}$ & 0.35 & 0.36 & 0.51 \\
\hline
\end{tabular}

Dependent variable ( $\mathrm{Zi}$ ) equals 0 for firms with a buy strategy, 1 for firms with a pseudo-make strategy, and 2 for firms with a make strategy.

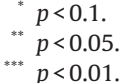

to be the same. ${ }^{9}$ This indicated that firms showed a strong tendency to pursue a make strategy over a buy strategy when dealing with an integral PA. One could also argue that the strategy choice of firms does not have to be specifically ordered and a firm pursuing a buy strategy could immediately pursue a make strategy in lieu of the pseudo-make strategy. In other words, firms can choose one of the three strategies without having to "pass through" another. With this in mind, we changed the strategy order coding and coded 0 for the pseudo-make strategy, 1 for the buy strategy, and 2 for the make strategy. Upon testing, the same significant results were obtained. ${ }^{10}$ It should be noted that we included the two instrumental variables, Number of Freewheel Suppliers and Market Demand Uncertainty, at this stage but excluded them at the second stage when dealing with the self-selection issue.

\subsection{Second-stage performance results}

Models 1-3 in Tables 4 and 5 show whether the independent variable $P A$ directly influences product performance. We begin by running a simple OLS regression, providing both OLS standard errors and the robust (cluster) corrected values in Model 1 of both Tables 4 and 5 . The three- or four-fold magnitude difference between the two error values in Model 1 in Tables 4 and 5 strongly indicates that there are invisible effects, at least at the firm level. This suggests that using OLS to estimate panel data can result in biased estimates because of unobserved heterogeneity. To correct for this bias, either fixed- or random-effects models can be used. We therefore performed a Hausman (1978) test to check which model proved better for the analysis, and the fixed-effects model prevailed. Both Models 2 and 3 in Tables 4 and 5 are fixed-effect models, but while Model 2 does not include dummy variables, Model 3 does include them. A comparison of Models 2 and 3 in Tables 4 and 5 demonstrate the importance of firm effects. Introducing a firm dummy variable for each firm into the regression substantially increased the log likelihood function, and the $R^{2}$ of the model rose from 0.391 to 0.759 in Table 4 and from 0.409 to 0.636 in Table 5. ${ }^{11}$ Notice that including firm dummies in the regression results in rather large changes to the coefficients of the control variables, confirming that some important determinants of product performance are not being captured in Model 2 of Tables 4 and 5 . The firm dummies served to capture a variety of firm-level effects such as the process capabilities of the firm, a factor which could not be accounted for by Firm Innovation Capabilities alone.

Product Architecture (PA) in both Model 3s of Tables 4 and 5 was negatively significant $(p<0.05)$, indicating that firms that adopted

\footnotetext{
9 Results are available upon request.

10 Results are available upon request.

11 Including or excluding Year Dummy in the models did not significantly affect $R^{2}$.
} 
Table 4

Second-stage estimation results (number of missed shiftings (SMOOTH) results).

\begin{tabular}{|c|c|c|c|c|c|c|c|}
\hline \multirow[t]{3}{*}{ (SMOOTH) } & \multicolumn{2}{|l|}{ Model 1} & \multirow{3}{*}{$\begin{array}{l}\text { Model } 2 \\
\text { Fixed-effect without firm } \\
\text { dummies }\end{array}$} & \multirow{3}{*}{$\begin{array}{l}\text { Model } 3 \\
\begin{array}{l}\text { Fixed-effect with firm } \\
\text { dummies }\end{array}\end{array}$} & \multicolumn{3}{|l|}{ Model 4} \\
\hline & \multicolumn{2}{|l|}{ OLS } & & & \multicolumn{3}{|c|}{$\begin{array}{l}\text { Fixed-effect with firm dummies } \\
\text { and mills ratio }\end{array}$} \\
\hline & Estimate & Std. err. ${ }^{a}$ & & & Buy & Pseudo-make & Make \\
\hline PA (Product Architecture) & $-0.012^{* *}$ & $\begin{array}{l}0.005 \\
(0.029)\end{array}$ & $\begin{array}{l}-0.175^{*} \\
(0.102)\end{array}$ & $\begin{array}{l}-0.247^{* *} \\
(0.101)\end{array}$ & $\begin{array}{l}-0.081^{*} \\
(0.248)\end{array}$ & $\begin{array}{l}-1.575^{* * *} \\
(0.161)\end{array}$ & $\begin{array}{l}-1.665^{* * *} \\
(0.551)\end{array}$ \\
\hline Derailleur Age & +0.018 & $\begin{array}{l}0.013 \\
(0.051)\end{array}$ & $\begin{array}{l}-0.004 \\
(0.013)\end{array}$ & $\begin{array}{l}+0.005^{*} \\
(0.003)\end{array}$ & $\begin{array}{l}-0.082 \\
(0.128)\end{array}$ & $\begin{array}{l}+0.064 \\
(0.166)\end{array}$ & $\begin{array}{l}+0.623 \\
(0.504)\end{array}$ \\
\hline Derailleur Complexity & $-0.237^{* * *}$ & $\begin{array}{l}0.031 \\
(0.182)\end{array}$ & $\begin{array}{l}-0.026^{*} \\
(0.014)\end{array}$ & $\begin{array}{l}-0.028^{* *} \\
(0.012)\end{array}$ & $\begin{array}{l}-2.061^{* * *} \\
(0.078)\end{array}$ & $\begin{array}{l}-1.825^{* * *} \\
(0.094)\end{array}$ & $\begin{array}{l}-2.217^{* * *} \\
(0.268)\end{array}$ \\
\hline Derailleur/Freewheel Sales & +0.020 & $\begin{array}{l}0.037 \\
(0.059)\end{array}$ & $\begin{array}{l}+0.018 \\
(0.015)\end{array}$ & $\begin{array}{l}+0.004 \\
(0.004)\end{array}$ & $\begin{array}{l}-0.030 \\
(0.058)\end{array}$ & $\begin{array}{l}-0.276^{* * *} \\
(0.054)\end{array}$ & $\begin{array}{l}-1.283^{* * *} \\
(0.202)\end{array}$ \\
\hline Duration of make, PM, and buy & $+0.014^{* *}$ & $\begin{array}{l}0.007 \\
(0.037)\end{array}$ & $\begin{array}{l}-0.027^{*} \\
(0.015)\end{array}$ & $\begin{array}{l}+0.022^{*} \\
(0.012)\end{array}$ & $\begin{array}{l}+0.161^{* * *} \\
(0.007)\end{array}$ & $\begin{array}{l}-0.314^{* * *} \\
(0.081)\end{array}$ & $\begin{array}{l}-0.109^{* * *} \\
(0.016)\end{array}$ \\
\hline Firm size & -0.067 & $\begin{array}{l}0.052 \\
(0.258)\end{array}$ & $\begin{array}{l}-0.297^{* * *} \\
(0.024)\end{array}$ & $\begin{array}{l}-0.149^{* * *} \\
(0.012)\end{array}$ & $\begin{array}{l}-0.183 \\
(0.187)\end{array}$ & $\begin{array}{l}-0.251^{*} \\
(0.132)\end{array}$ & $\begin{array}{l}-0.525^{*} \\
(0.297)\end{array}$ \\
\hline Firm Innovation Cap. & $-0.093^{* *}$ & $\begin{array}{l}0.039 \\
(0.151)\end{array}$ & $\begin{array}{l}-0.007^{*} \\
(0.004)\end{array}$ & $\begin{array}{l}-0.034^{*} \\
(0.018)\end{array}$ & $\begin{array}{l}+0.249 \\
(0.159)\end{array}$ & $\begin{array}{l}-0.546^{* * *} \\
(0.121)\end{array}$ & $\begin{array}{l}-1.834^{* * *} \\
(0.179)\end{array}$ \\
\hline Firm Age & -0.016 & $\begin{array}{l}0.030 \\
(0.250)\end{array}$ & $\begin{array}{l}+0.108 \\
(0.103)\end{array}$ & $\begin{array}{l}-0.028 \\
(0.103)\end{array}$ & $\begin{array}{l}-0.093 \\
(0.118)\end{array}$ & $\begin{array}{l}-0.154 \\
(0.125)\end{array}$ & $\begin{array}{l}-0.066 \\
(0.176)\end{array}$ \\
\hline Firm Dummy (26) & & & & 15 Firm $_{* * *}^{* * *}$ & $12 \operatorname{Firm}_{* * *}^{* * *}$ & $14 \operatorname{Firm}_{* * * *}^{* * *}$ & 16 Firm $_{* * * *}^{* * *}$ \\
\hline Year Dummy (12) & & & 1 year $^{* * *}$ & 1 year $^{* *}$ & 1 year $^{* * *}$ & 1 year $^{* * *}$ & 1 year $^{* * *}$ \\
\hline Inverse Mills ratio - buy & & & & & $\begin{array}{l}-0.446 \\
(0.359)\end{array}$ & & \\
\hline Inverse Mills ratio - pseudo-make & & & & & & $\begin{array}{l}+0.773^{*} \\
(0.421)\end{array}$ & \\
\hline Inverse Mills ratio - make & & & & & & & $\begin{array}{c}-0.472 \\
(0.782)\end{array}$ \\
\hline Constant & $4.158^{* * *}$ & $\begin{array}{l}0.015 \\
(0.071)\end{array}$ & $\begin{array}{l}2.178^{* * *} \\
(0.131)\end{array}$ & $\begin{array}{l}4.143^{* * *} \\
(0.101)\end{array}$ & $\begin{array}{l}8.125^{* * *} \\
(0.424)\end{array}$ & $\begin{array}{l}13.193^{* * *} \\
(0.601)\end{array}$ & $\begin{array}{l}11.211^{* * *} \\
(2.262)\end{array}$ \\
\hline$N$ & 492 & 492 & 492 & 280 & 110 & 102 & \\
\hline $\log L$ & -1829 & -1659 & -924 & & & & \\
\hline Adjusted $R^{2}$ & 0.388 & 0.391 & 0.759 & 0.698 & 0.743 & 0.781 & \\
\hline
\end{tabular}

integral PAs were more likely to exhibit better product performance than firms that did not. Since index shifting technology significantly improved shifting performance, performance gaps between conventional and index shifting systems were large and bikes without index technology did not sell well (Bicycling, March 1987, p. 38). Not surprisingly, firms adopting the integral PA embodying index shifting technology were likely to show better product performance.

Model 4 of Tables 4 and 5 is relevant to the interaction effect between PA choice and the make/pseudo-make/buy decision on product performance, which is of major interest to this study. The coefficient estimate comparisons in Tables 4 and 5 indicate the impact of 'only' integral PAs on product performance for the M/PM/B strategies. To complement the unidirectional analysis of Tables 4 and 5 , this study adds Figs. 1(a), 1(b), 2(a), 2(b), 3(a) and 3(b). (a) in Figs. 1-3 is relevant to $S M O O T H$, and (b) in Figs. 1-3 is relevant to DMG. These figures focus on the performance comparisons of the three strategies for integral and modular PAs (Aiken and West, 1991). By holding all variables at their respective means and varying types of PAs, they compare the product performances of firms with the M/PM/B strategies when dealing with a modular or integral PA.

Model 4 also adds the inverse Mills ratio (Lambda, $\lambda$ ). The inverse Mills ratios given in Model 4 of Table 4 for the pseudo-make strategy are significant, interpreted as the unobserved characteristics of the pseudo-make strategy influencing product performance relative to the other strategies. However, the inverse Mills ratios in the buy and make strategies are not significant. This may suggest that the impact of unobserved characteristics of firms with a buy or make strategy on product performance is negligible. Regarding the inverse Mills ratios in Model 4 of Table 5, the inverse Mills ratios for the buy and pseudo-make strategy are significant, denoting that unobserved characteristics of the buy and pseudo-make strategy influence product performance. However, the inverse Mills ratio for the make strategy is not significant, indicating that unobserved characteristics of the make strategy negligibly influence product performance.

Comparing the $R^{2}$ of Models 2 and 3, we see that adding firm dummy variables explains a substantial improvement of the $R^{2}$. However, adding the inverse Mills ratios does not appear to improve the $R^{2}$ in Model 4 of Tables 4 and 5. This reflects the fact that the firm dummy variables and the inverse Mills ratios may not be orthogonal. These ratios represent unobserved characteristics of a firm's M/PM/B strategy, and the unobserved characteristics may already be embodied by the firm dummy variables representing any unobserved organizational factors. In fact, though individual correlation coefficients between the firm dummy variables and the inverse Mills ratios are not particularly high, the two sets of variables may essentially span the same space causing the addition of the inverse Mills ratios to not improve the $R^{2}$ significantly.

Regarding the interaction coefficients between the PA and the $\mathrm{M} / \mathrm{PM} / \mathrm{B}$ strategy choice in Model 4 of Tables 4 and 5, we first compare the $P A$ coefficients of the buy and make strategies. Notice that the $P A$ coefficients in Model 3 of Tables 4 and 5 are negatively significant (both $p<0.05$ ). However, the PA coefficient of the buy strategy in Model 4 becomes less significant than the PA coefficient in Model 3 of Table $4(-0.081, p<0.1)$. Moreover, the $P A$ coefficient of the buy strategy in Model 4 of Table 5 is not significant even with a positive sign $(+0.479)$. These results suggest that for product performance 
Table 5

Second-stage estimation results (derailleur movement gap (DMG) results).

\begin{tabular}{|c|c|c|c|c|c|c|c|}
\hline \multirow[t]{3}{*}{ (DMG) } & \multicolumn{2}{|l|}{ Model 1} & \multirow{3}{*}{$\begin{array}{l}\text { Model } 2 \\
\text { Fixed-effect without firm } \\
\text { dummies }\end{array}$} & \multirow{3}{*}{$\begin{array}{l}\text { Model } 3 \\
\begin{array}{l}\text { Fixed-effect with firm } \\
\text { dummies }\end{array}\end{array}$} & \multicolumn{3}{|l|}{ Model 4} \\
\hline & \multicolumn{2}{|l|}{ OLS } & & & \multicolumn{3}{|c|}{$\begin{array}{l}\text { Fixed-effect with firm dummies } \\
\text { and mills ratio }\end{array}$} \\
\hline & Estimate & Std. err. ${ }^{a}$ & & & Buy & Pseudo-make & Make \\
\hline PA (Product Architecture) & $-0.027^{* *}$ & $\begin{array}{l}0.011 \\
(0.047)\end{array}$ & $\begin{array}{l}-0.772^{* *} \\
(0.351)\end{array}$ & $\begin{array}{l}-0.823^{* *} \\
(0.375)\end{array}$ & $\begin{array}{l}+0.479 \\
(0.209)\end{array}$ & $\begin{array}{l}-2.946^{* * *} \\
(0.131)\end{array}$ & $\begin{array}{l}-2.744^{* * *} \\
(0.531)\end{array}$ \\
\hline Derailleur Age & $-0.036^{* *}$ & $\begin{array}{l}0.015 \\
(0.051)\end{array}$ & $\begin{array}{l}-0.126^{* *} \\
(0.050)\end{array}$ & $\begin{array}{l}-0.022 \\
(0.069)\end{array}$ & $\begin{array}{l}-0.009 \\
(0.100)\end{array}$ & $\begin{array}{l}+0.005 \\
(0.138)\end{array}$ & $\begin{array}{l}-0.095 \\
(0.311)\end{array}$ \\
\hline Derailleur Complexity & -0.312 & $\begin{array}{l}0.212 \\
(0.034)\end{array}$ & $\begin{array}{l}-0.105^{* *} \\
(0.048)\end{array}$ & $\begin{array}{l}+0.214^{* *} \\
(0.101)\end{array}$ & $\begin{array}{l}-0.167^{*} \\
(0.088)\end{array}$ & $\begin{array}{l}-0.132^{*} \\
(0.070)\end{array}$ & $\begin{array}{l}-0.430^{*} \\
(0.227)\end{array}$ \\
\hline Derailleur/Freewheel Sales & $+0.077^{* * *}$ & $\begin{array}{l}0.012 \\
(0.041)\end{array}$ & $\begin{array}{l}+0.033^{*} \\
(0.019)\end{array}$ & $\begin{array}{l}-0.009 \\
(0.026)\end{array}$ & $\begin{array}{l}-0.091^{*} \\
(0.052)\end{array}$ & $\begin{array}{l}-0.055^{* * *} \\
(0.032)\end{array}$ & $\begin{array}{l}-0.096^{* * *} \\
(0.138)\end{array}$ \\
\hline Duration of make, PM, and buy & $-0.037^{* *}$ & $\begin{array}{l}0.016 \\
(0.068)\end{array}$ & $\begin{array}{l}-0.026^{* *} \\
(0.011)\end{array}$ & $\begin{array}{l}-0.002^{*} \\
(0.001)\end{array}$ & $\begin{array}{l}+0.265^{* * *} \\
(0.081)\end{array}$ & $\begin{array}{l}-0.346^{* * *} \\
(0.051)\end{array}$ & $\begin{array}{l}-0.399^{* * *} \\
(0.108)\end{array}$ \\
\hline Firm size & -0.002 & $\begin{array}{l}0.001 \\
(0.002)\end{array}$ & $\begin{array}{l}-0.149^{* * *} \\
(0.019)\end{array}$ & $\begin{array}{l}-0.004^{* *} \\
(0.002)\end{array}$ & $\begin{array}{l}-3.989^{* * *} \\
(0.187)\end{array}$ & $\begin{array}{l}-0.267^{* *} \\
(0.119)\end{array}$ & $\begin{array}{l}-2.245^{* * *} \\
(0.231)\end{array}$ \\
\hline Firm Innovation Cap. & $+0.036^{*}$ & $\begin{array}{l}0.019 \\
(0.050)\end{array}$ & $\begin{array}{l}-0.087^{*} \\
(0.048)\end{array}$ & $\begin{array}{l}-0.161^{* *} \\
(0.067)\end{array}$ & $\begin{array}{l}-0.891^{* *} \\
(0.401)\end{array}$ & $\begin{array}{l}-1.136^{* * *} \\
(0.260)\end{array}$ & $\begin{array}{l}-0.440^{* *} \\
(0.173)\end{array}$ \\
\hline Firm Age & +0.018 & $\begin{array}{l}0.013 \\
(0.061)\end{array}$ & $\begin{array}{l}+0.075 \\
(0.121)\end{array}$ & $\begin{array}{l}-0.042^{*} \\
(0.022)\end{array}$ & $\begin{array}{l}-0.798^{*} \\
(0.448)\end{array}$ & $\begin{array}{l}-0.166 \\
(0.227)\end{array}$ & $\begin{array}{l}-0.076 \\
(0.117)\end{array}$ \\
\hline Firm Dummy (26) & & & & 13 Firm $^{* * *}$ & 10 Firm $^{* * *}$ & 13 Firm $^{* * *}$ & 13 Firm $^{* * *}$ \\
\hline $\begin{array}{l}\text { Year Dummy (12) } \\
\text { Inverse Mills ratio - buy }\end{array}$ & & & 1 year $^{* * *}$ & 1 year $^{* * *}$ & $\begin{array}{l}1 \text { year }^{* *} \\
-0.403^{* * *} \\
(0.101)\end{array}$ & 1 year $^{* *}$ & 1 year $^{* *}$ \\
\hline Inverse Mills ratio - pseudo-make & & & & & & $\begin{array}{l}-0.519^{* *} \\
(0.206)\end{array}$ & \\
\hline Inverse Mills ratio - make & & & & & & & $\begin{array}{l}0.323 \\
(0.618)\end{array}$ \\
\hline Constant & $8.926^{* * *}$ & $\begin{array}{l}0.025 \\
(0.214)\end{array}$ & $\begin{array}{l}9.356^{* * *} \\
(0.244)\end{array}$ & $\begin{array}{l}9.249^{* * *} \\
(0.368)\end{array}$ & $\begin{array}{l}22.577^{* * *} \\
(0.787)\end{array}$ & $\begin{array}{l}15.207^{* * *} \\
(2.070)\end{array}$ & $\begin{array}{l}16.068^{* * *} \\
(1.678)\end{array}$ \\
\hline$N$ & 492 & 492 & 492 & 280 & 110 & 102 & \\
\hline $\log L$ & -1623 & -1581 & -745 & & & & \\
\hline Adjusted $R^{2}$ & 0.401 & 0.409 & 0.636 & 0.556 & 0.601 & 0.681 & \\
\hline
\end{tabular}

improvement, it is not enough to just adopt the new technology, but to also adopt the appropriate make-buy strategy corresponding to the new technology. In this study, the buy strategy would prove to be problematic in dealing with the new index shifting technology and its integral PA, causing deterioration of product performance. Firms with a buy strategy would find it difficult to acquire and share the technical knowledge to efficiently deal with the innate complexities of index shifting technology.

Contrastingly, $P A$ is significantly negative for firms with a make strategy ( -1.665 and -2.744 in Tables 4 and 5, respectively, $p<0.01$ ), a significant improvement from the $P A$ coefficients of both Model 3s in Tables 4 and 5. This suggests that firms which adopted index shifting technology could improve shifting performance by choosing a make strategy. In dealing with index shifting technology, firms with a make strategy may be in a better position for knowledge sharing and coordination so as to improve shifting performance. Clearly, the results regarding the make vs. buy strategies suggest that when dealing with an integral PA, firms following a make strategy are likely to show better product performance than firms following a buy strategy. When considering Fig. 1(a) and (b) (a)

\section{Interaction Effect b/w PA and Buy vs. Make on} SMOOTH

(b)

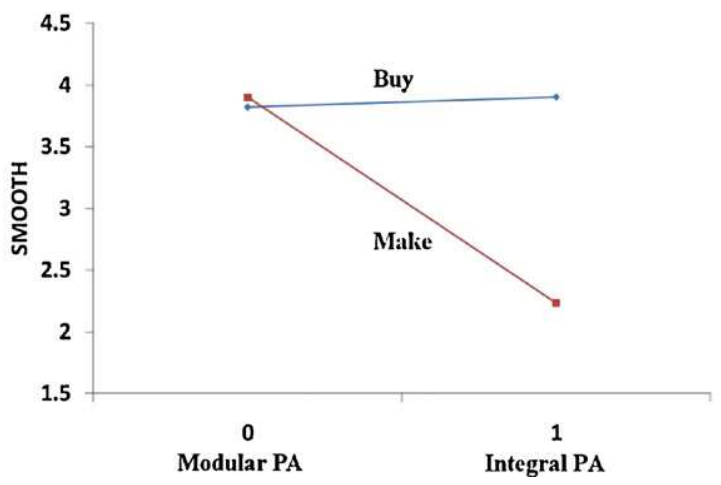

Interaction Effect b/w PA and Buy vs. Make on DMG

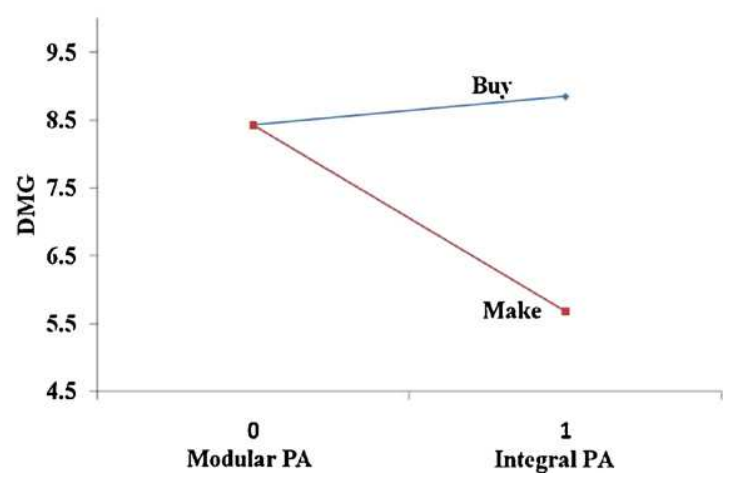

Fig. 1. (a) Interaction effect b/w PA and buy vs. make on SMOOTH. (b) Interaction effect b/w PA and buy vs. make on DMG. 
(a) Interaction Effect b/w PA and Buy vs. Pseudo-Make on SMOOTH

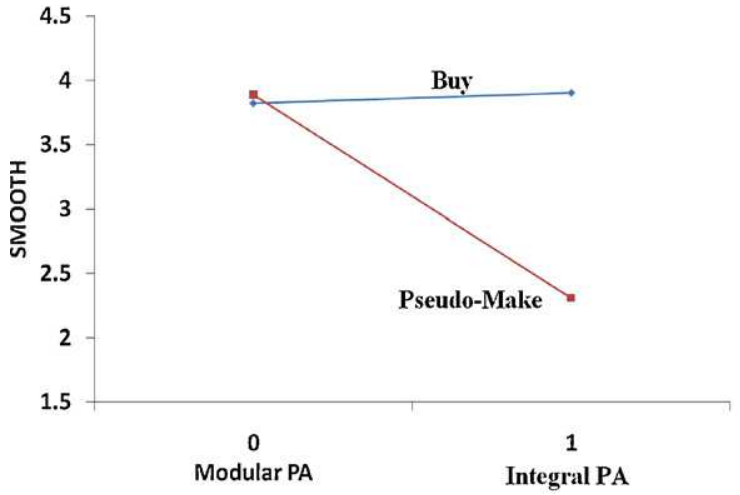

(b) Interaction Effect b/w PA and Buy vs. Pseudo-Make on DMG

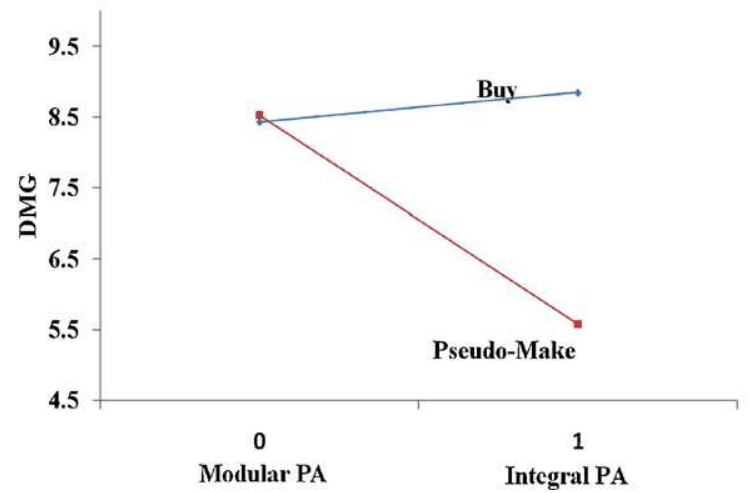

Fig. 2. (a) Interaction effect b/w PA and buy vs. pseudo-make on SMOOTH. (b) Interaction effect b/w PA and buy vs. pseudo-make on DMG.

(in addition to Tables 4 and 5), and focusing on the product performance comparisons of the three (M/PM/B) strategies for an integral and modular PA, we find that in dealing with an integral PA, firms pursuing a make strategy show better SMOOTH performance than firms with a buy strategy by $43 \%$, and better $D M G$ performance by $37 \%$. This suggests that when dealing with an integral PA, firms adopting a make strategy displayed superior product performance to firms adopting a buy strategy. Thus, Hypothesis 1 is strongly supported in this test. However, in dealing with a modular PA, the performance gap between firms with a buy strategy and those with a make strategy is negligible. When dominant PAs are standardized and modular, the prevailing competitive concepts for firms tend to focus on component diversification and cost reduction rather than on providing better product performance (Christensen et al., 2002). However, index shifting technology caused the dominant PA to switch from modular to integral form, and this change created unforeseen challenges for firms with a buy strategy to overcome compared to firms that chose to follow a make strategy (in terms of decreasing SMOOTH and DMG).

Notably, the coefficients of the pseudo-make strategy model in Tables 4 and 5 are negatively significant $(-1.665$ and -2.744 in Tables 4 and 5, respectively, with $p<0.01$ for both). The level of significance is greater than the $P A$ coefficients in Model 3 of Tables 4 and $5(-0.247$ and -0.823 , respectively, with $p<0.05$ for both). These results suggest that firms could have improved product performance to a greater extent by pursuing both a pseudomake strategy along with adopting the index shifting technology as opposed to just simply adopting index shifting technology alone based on the integral PA. And as mentioned before, the PA coefficient of the buy strategy model in Table 4 is negatively significant $(-0.081, p<0.1)$ and not significant but positive $(+0.479)$ in Table 5. Juxtaposing the coefficients of $P A$ between the pseudo-make and buy strategies would indicate that in the integral PA context, firms pursuing the pseudo-make strategy would exhibit superior product performance to firms pursuing the buy strategy. The pseudo-make strategy might be better in facilitating knowledge sharing and creating a single communication code (Monteverde, 1995) than the buy strategy so that firms with a pseudo-make strategy can more efficiently deal with complexity issues of index shifting technology than firms with a buy strategy. Although both the buy and pseudomake strategies use an outsourcing approach, the results of this study indicate that the implications for product performance are quite distinct between the two strategies. Moreover, as in Fig. 2(a) and (b), in dealing with an integral PA, firms with a pseudo-make strategy clearly outperformed firms with a buy strategy by $42 \%$ and $37 \%$ in terms of SMOOTH and DMG, respectively. Therefore, Hypothesis 2 is also strongly supported. However, similar to the case between the make and buy strategies, when dealing with a modular PA, firms with a buy strategy did not show significant product performance differences from firms with a pseudo-make strategy. This is again believed to stem from firms competing for cost reductions or component diversity rather than on improved product performance when dealing with a modular PA (Fine, 1998; Christensen et al., 2002).

Lastly, comparing the impact of the make and pseudo-make strategies on product performance, Model 4 in Tables 4 and 5 shows (a) Interaction Effect b/w PA and Make vs. Pseudo-Make on SMOOTH

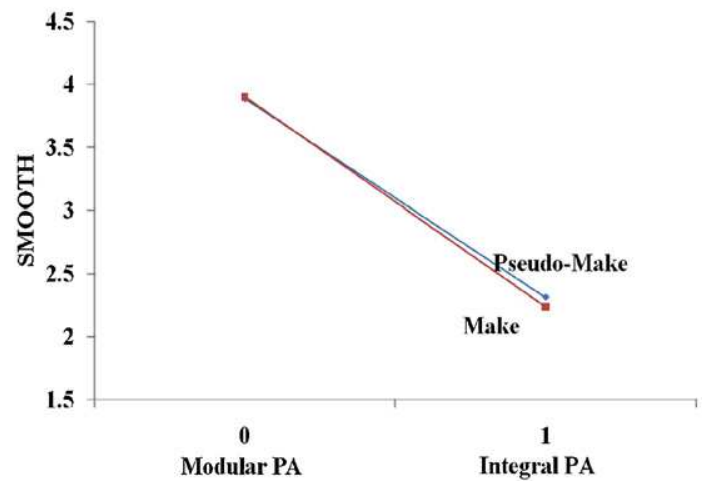

(b) Interaction Effect b/w PA and Make vs. Pseudo-Make on DMG

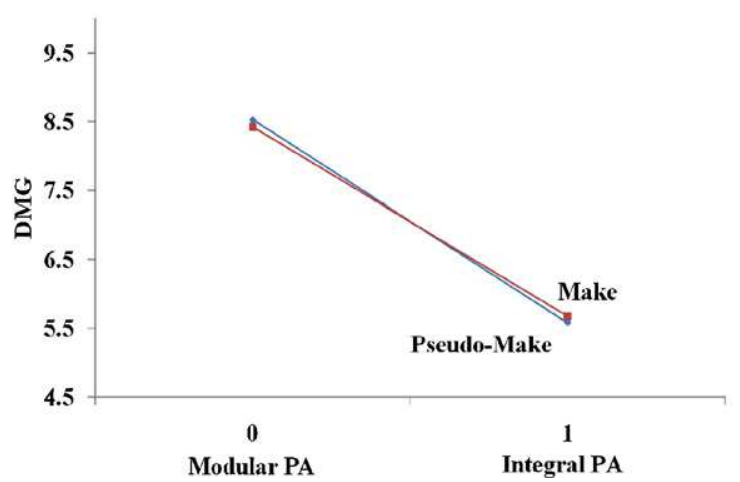

Fig. 3. (a) Interaction effect $\mathrm{b} / \mathrm{w} \mathrm{PA}$ and make vs. pseudo-make on SMOOTH. (b) Interaction effect b/w PA and make vs. pseudo-make on DMG. 
that firms utilizing the make strategy seemed to exhibit similar product performance to firms utilizing a pseudo-make strategy with both coefficients being negatively significant $(p<0.01)$. In addition, a comparison of product performance between the make and pseudo-make strategies in Fig. 3(a) and (b) shows that the difference of product performance between the two strategies seemed negligible when dealing with both integral and modular PAs. In dealing with the integral PA, in terms of SMOOTH, firms with a make strategy seemed to slightly outperform firms with a pseudomake strategy; in terms of $D M G$, firms with a pseudo-make strategy seemed to slightly outperform firms with a make strategy. But both cases did not show any statistically significant performance gaps. Therefore, Hypothesis 3 is not strongly supported. However, this finding is still very meaningful since it suggests that when dealing with an integral PA, firms adopting a pseudo-make strategy could yield similar product performance to firms adopting a pure make strategy. The findings of this study indicate that even if a firm uses a buy strategy, if it can keep design capability (or requisite design knowledge) in-house (i.e. the pseudo-make strategy), the firm could yield product performance on a similar level to that of firms following a make strategy.

\section{Discussion and implications}

As stated in Section 1, most of the relevant PA and M/B choice literature focuses on one predominant evolutionary direction - the integral-to-modular PA change. However, a few studies reside in the opposite evolutionary direction and suggest that as PA changes from modular to integral form, firms are likely to change their strategy from a buy to a make strategy. These works are based on the presumption that in dealing with an integral PA, firms with a make strategy are likely to outperform those with a buy strategy. Given the lack of empirical testing, the purpose of this study is to theoretically and empirically validates this presumption by exploring the U.S. bicycle derailleur/freewheel market from 1980 to 1992. Prior to index shifting technology, the PA of the derailleur and freewheel was modular and standardized in form. Competition between firms resided in cost reduction efforts and component diversity development rather than product innovation or superior product performance (Fixson and Park, 2008). In truth, the bicycle derailleur and freewheel market also showed that under the modular PA paradigm, product performance (as measured by SMOOTH and $D M G$ ) was not significant between different strategies. However, once index shifting technology was introduced in 1985, the new technology shifted the dominant PA in the market from modular to integral form and the concept of competition changed to from cost reduction to product performance. As a result of the shift, optimally designing the chain gap (i.e. the linkages between the derailleur and freewheel) became quite complex and critical for desirable shifting performance, an issue not of great concern in the older conventional driving-train sets (Fixson and Park, 2008). Given the occurrence of a significant PA shift from modular to integral form, this study empirically tested the product performance of firms with different $\mathrm{M} / \mathrm{PM} / \mathrm{B}$ strategies.

\subsection{Theoretical and managerial contribution}

This study provides several valuable contributions to both academics and practitioners alike. Regarding academic contributions, this study first provides empirical evidence for the relationship between PA and M/PM/B strategic choices and their impact on product performance in the face of an integral PA. Despite the general acceptance of the theoretical models, little empirical evidence exists to establish a wide industry base of support for them. The rigorous testing provided in this study can prove valuable in establishing a basis of some empirical evidence to the current literature.

Second, this study bridges theories from the KBV and firm/knowledge boundary literature with the PA and M/B choice literature. By doing so, this study provides a more clear understanding of different sourcing strategies firms can pursue in the face of modular-to-integral PA change in a manner that no one literature body can do in isolation. By integrating the KBV and firm/knowledge boundary literature with the PA and M/B literature, this study highlights a distinction between the buy, pseudo-make, and make strategies that has not been fully appreciated. The main thrust of our study is that there is a type of outsourcing strategy in between the pure buy and make strategies - the pseudo-make strategy (a hybrid strategy where the manufacturing function is outsourced but the knowledge capability is kept in-house) - that allows firms to capitalize on gaining and share knowledge dealing with high-complexity integral PAs (due to the high component interdependence). As explained earlier, much of the existing literature (Fine, 1998; Baldwin and Clark, 2000; Christensen et al., 2002) categorizes firms into two typologies: those that pursue a make strategy and those that pursue a buy strategy. This dichotomous categorization of sourcing strategies has been well established in the literature for quite some time (e.g. TCE). With their emphasis on the dichotomous choice between make and buy, earlier scholarly works presume that when dealing with an integral PA, firms pursuing a make strategy are likely to outperform firms following a buy strategy. However, with the make/pseudo-make/buy categorization, we found that derailleur firms with a pseudo-make strategy in the bicycle industry showed significantly better product performance than firms with a buy strategy, and firms with a pseudo-make strategy showed similar product performance to firms with a make strategy. These results suggest that even firms engaged in outsourcing activities can offer product performance at a similar level to those firms with a make strategy, provided that proper knowledge integration and task coordination mechanisms are in place while keeping design capability in-house. Our findings, thus, imply that the presumption of the previous works might be somewhat overly simplified.

Since the presumption might not always be true, this study accordingly places a question mark on the suggestion of the earlier works that as PA changes from modular to integral form, firms will likely pursue a make strategy over a buy strategy. The findings highlight an important distinction between the pseudo-make and buy strategies that has not previously been fully appreciated and as a result increases our understanding of why some firms do not switch strategies when PA changes from modular to integral form. As a case in point, Hoetker (2006) investigated the relationship between PA change and the firm boundary decision in the notebook computer industry. He studied the make-buy decision among notebook computer manufacturers when dealing with an integrated PA and categorized firms as pursuing either a make or buy strategy (the pseudo-make strategy was excluded). He discovered that notebook computer makers did not exhibit a strong propensity to pursue a make strategy when faced with a newly introduced integral PA, but rather, tended to stay put with their existing buy strategy. Our findings could provide some hints as to why these firms preferred the buy strategy over the make strategy. ${ }^{12}$ One possible conjecture is that firms adopting a pseudo-make strategy, categorized as a buy strategy in Hoetker (2006), may not be strongly motivated to change to a make strategy since with their pseudo-make strategy, they are able to deal with the new integral PA as well as any firm

\footnotetext{
12 We are fully aware of how risky it is to interpret another scholar's results with our current findings. Our conjectures are, thus, aptly stated.
} 
adopting a make strategy. ${ }^{13}$ Therefore, given the theoretical and managerial implications, the results given in our study suggest the necessity for more careful theoretical and empirical investigation of the impact of linkages between PAs and firm sourcing decisions on product performance.

The findings of this study also provide some valuable managerial implications regarding the firm outsourcing decision. Sometimes firms find themselves in situations where control of all relevant components via a make strategy may be difficult or nigh impossible. Once an industry has adopted a standardized PA, a firm's capability to quickly customize and provide better product features to customers becomes key to maintaining sustainable advantages (Christensen et al., 2002). Therefore, independent component firms can thrive in the market and enjoy more economies of scale than vertically integrated firms in the context of a standardized modular PA (Christensen and Rosenbloom, 1995; Baldwin and Clark, 2000). When the dominant PA for the drive train component set in the bicycle industry was modular, firms with a buy strategy seemed to enjoy such advantages. However, as the findings in this study indicate, when faced with innovations associated with integral PAs, firms need to be cautious with their choice of buy strategy as it can lead to a more complicated operating environment concerning vital knowledge sharing and integration issues. This integrated architecture paradigm is likely to give product performance advantages to firms favoring a pseudo-make strategy over firms in a pure outsourcing scenario. With a pseudo-make strategy, firms in the bicycle industry could enjoy knowledge management and organizational process advantages that allowed for a higher performing index shifting system than firms with a pure buy strategy. By being in an outsourcing situation in the first place, firms with a buy strategy found themselves in situations where they might confront knowledge integration and supplier opportunism problems. They also had to expend the time and energy to properly integrate their processes with those of their suppliers. It may be, therefore, critical that practicing managers have a clear understanding of the linkages between components and keep design knowledge in-house even in the face of a required outsourcing decision.

\section{Limitations and future research}

Regarding limitations and suggestions for future research, the most obvious is that this study focuses on a single industry, making generalizations across different industries challenging. In some industries, however, such as the disk drive (Christensen et al., 2002), PC (Fine, 1998), and watch (Jacobides and Winter, 2005) industries, PAs are evolving towards integrated structures. Investigating these industries along similar lines of study might prove to be meaningful.

Second, this study focuses on the impact of a firm's strategic $\mathrm{M} / \mathrm{PM} / \mathrm{B}$ decision on product performance. It does not, however, focus on a firm's strategic decision in the face of an integral PA. When considering the evolution of PA from modular to integral form, a firm's behavior regarding the M/PM/B decision may be a research topic worthy of pursuit. One meaningful question is, "Why do some firms move to adopt a make strategy, and why do others stay put with their current buy strategy?" If the change of PA is the only factor affecting a firm's outsourcing strategy, similarities in firm behavior should be observed whenever a PA changes from modular to integral form. However, in such situa-

\footnotetext{
13 Of course, there may be other reasons as to why firms do not pursue a make strategy when dealing with an integral PA. For example, firms that stay entrenched with a buy strategy in the face of an integral PA may not realize the importance of the appropriate alignment for certain types of product architectures and may end up being stuck in organizational inertia (e.g. Hannan and Freeman, 1977; Nelson and Winter, 1982)
}

tions, firms often show heterogeneous make-buy choices (Hoetker, 2005, 2006). Many factors could come into affect here. For example, performance feedback could affect a firm's strategic behavior. As this study has shown, firms with a pseudo-make strategy exhibited similar product performance to firms with a make strategy. Thus, many firms may not feel a strong compulsion to change their outsourcing practice. However, if the product performance of those firms following a pseudo-make strategy was sub-par, firms could have behaved quite differently. In essence, combining a firm's performance-aspiration feedback model with its strategic behavior would be an interesting research investigation. Another example involves the relationship between a firm and its outsourcing partner. If a firm and particular partner have built up a long term committed working relationship, they might build up mutual trusts which result in better product performance. Thus, looking into the impact of the relationship between a firm and its supplier partner with regards to firm behavior and its implication for product performance would also be worthwhile. Lastly, this study finds that in the bicycle industry, firms with a make or pseudo-make strategy clearly show better product performance than firms possessing alternative governance modes in dealing with index shifting technology. This study attempts to shed some light on which strategies firms should pursue in dealing with integral PAs from the perspective of knowledge sharing, transfer, and integration, but does not provide clear reasons as to why firms adopting a make or pseudo-make strategy are better than firms incorporating purely a buy strategy. Investigating specific reasons as to why firms adopting a make or pseudo-make strategy perform better than firms incorporating a buy strategy, or why firms following a pseudo-make strategy show similar product performance to firms adopting a make strategy, would also be valuable. Hence, using in-depth case study analysis to look at the 'why' of this particular issue could provide further insight into this interesting and important phenomenon.

\section{References}

Afuah, A., 2001. Dynamic boundaries of the firm: are firms better off being vertically integrated in the face of a technological change? Academy of Management Journal 44 (6), 1211-1228.

Aiken, L.S., West, S.G., 1991. Multiple Regression: Testing and Interpreting Interactions. Sage Publications, Inc.

Akerlof, G.A., 1970. The market for lemons: quality uncertainty and the market mechanism. The Quarterly Journal of Economics 84, 488-500.

Alston, L.J., Gillespie, W., 1989. Resource coordination and transaction costs. Journal of Economic Behavior and Organization 11, 191-212.

Amburgey, T.L., Kelly, D., et al., 1993. Resetting the clock: the dynamics of organizational change and failure. Administrative Science Quarterly 38, 51-73.

Baldwin, C., 2007. Where do transactions come from? Modularity, transactions, and the boundaries of firms. Industrial and Corporate Change 17 (1), 155-195.

Baldwin, C.Y., Clark, K.B., 2000. Design Rules: The Power of Modularity. MIT Press, Cambridge, MA.

Barnett, W.P., 1990. The organizational ecology of a technological system. Administrative Science Quarterly 35, 31-60.

Barney, J., 1991. Firm resources and sustained competitive advantage. Journal of Management 17, 99-120.

Berto, F., 2005. The Dancing Chain: History and Development of the Derailleur Bicycle, 2nd edition. Van der Plas Publications/Cycle Publishing, San Francisco.

Bowen, H.P., Wiersema, M.F., 1999. Matching method to paradigm in strategy research: limitations of cross-sectional analysis and some methodological alternatives. Strategic Management Journal 20 (7), 625-636.

Brown, S.L., Eisenhardt, K.M., 1997. The art of continuous change: linking complexity theory and time-paced evolution in relentlessly shifting organizations. Administrative Science Quarterly 42, 1-34.

Brusoni, S., 2005. The limits to specialization: problem solving and coordination in 'modular networks'. Organization Studies 26 (12), 1885-1907.

Brusoni, S., Prencipe, A., 2006. Making design rules: a multidomain perspective. Organization Science 17 (2), 179-189.

Brusoni, S., Prencipe, A., Pavitt, K., 2001. Knowledge specialization, organizational coupling, and the boundaries of the firm: why do firms know more than they make? Administrative Science Quarterly 46, 597-621.

Christensen, C.M., 1997. The Innovator's Dilemma: When New Technologies Cause Great Firms to Fail. Harvard Business School Press, Boston, MA.

Christensen, C.M., Rosenbloom, R.S., 1995. Explaining the attacker's advantage: technological paradigms. organizational dynamics, and the value network. Research Policy 24, 233-257. 
Christensen, C.M., Verlinden, M., et al., 2002. Disruption, disintegration and the dissipation of differentiability. Industrial and Corporate Change 11 (5), 955-993.

Cohen, W.M., Klepper, S., 1996. A reprise of size and R\&D. The Economic Journal 106 (437), 925.

Cohen, W.M., Levinthal, D.A., 1990. Absorptive capacity: a new perspective on learning and innovation. Administrative Science Quarterly 35 (1), 128-152.

Conner, K.R., Prahalad, C.K., 1996. A resource-based theory of the firm: knowledge versus opportunism. Organization Science 7, 477-501.

D’Aveni, R.A., Ravenscraft, D.J., 1994. Economies of integration versus bureaucracy costs: does vertical integration improve performance? Academy of Management Journal 37 (5), 1167.

Demsetz, H., 1988. The theory of the firm revisited. Journal of Law, Economics \& Organization 4 (1), 141-162.

Dess, G.G., Beard, D.W., 1984. Dimensions of organizational task environments. Administrative Science Quarterly 29 (1), 52-73.

Dosi, G., Hobday, M., et al., 2003. The economics of system integration: toward an evolutionary interpretation. In: Prencipe, A., Davies, A., Hobday, M. (Eds.), Business of Systems Integration. Oxford University Press, New York, pp. 78-91.

Dyer, J.H., 1997. Effective interfirm collaboration: how firms minimize transaction costs and maximize transaction value. Strategic Management Journal 18 (7), 535-556.

Fine, C.H., 1998. Clockspeed: Winning Industry Control in the Age of Temporary Advantage. Perseus Books, Reading, MA.

Fixson, S.K., Park, J.-K., 2008. The power of integrality: linkages between product architecture, innovation, and industry structure. Research Policy 37 (8), 1296-1316.

Garud, R., Kumaraswamy, A., et al., 2002. Managing in the Modular Age: Architectures, Networks and Organizations. Blackwell.

Grant, R.M., 1996. Toward a knowledge-based theory of the firm. Strategic Management Journal 17, 109-122.

Greene, W.H., 2003. Econometric Analysis. Prentice Hall, Upper Saddle River, NJ.

Gulati, R., 1995. Does familiarity breed trust? The implications of repeated ties for contractual choice in alliance. Academy of Management Journal 38 (1), 85-112.

Hamilton, B.H., Nickerson, J.A., 2003. Correcting for endogeneity in strategic management research. Strategic Organization 1 (1), 51-78.

Hammond, T.H., Miller, G.J., 1985. A social choice perspective on expertise and authority in bureaucracy. American Journal of Political Science 29 (1), 1-28.

Hannan, M.T., Freeman, J., 1977. The population ecology of organizations. American Journal of Sociology 82, 929-964.

Harrigan, K.R., 1984. Formulating vertical integration strategies. Academy of Management Journal 9, 638-652.

Hausman, J.A., 1978. Specification tests in econometrics. Econometrica 46, $1251-1271$.

Hausman, J., Hall, B.H., 1984. Econometric models for count data with an application to the patents-relationship. Econometrica 52, 909-938

Heckman, J.J., 1979. Sample selection bias as a specification error. Econometrica 47 (1), 153-161.

Henderson, R., Clark, K., 1990. Architectural innovation: the reconfiguration of existing. Administrative Science Quarterly 35 (1), 9-30.

Hoetker, G., 2005. How much you know versus how well I know you: selecting a supplier for a technically innovative component. Strategic Management Journal 26, 75-96.

Hoetker, G., 2006. Do modular products lead to modular organizations? Strategic Management Journal 27, 501-518.

Jacobides, M.G., Winter, S.G., 2005. The co-evolution of capabilities and transaction costs: explaining the institutional structure of production. Strategic Management Journal 26, 395-413.

Kennedy, P.E., 2003. A Guide to Econometrics, 5th edition. The MIT Press.

Klein, K.J., Kozlowski, S.W.J., 2000. Multilevel Theory, Research, and Methods in Organizations: Foundations, Extensions, and New Directions. Pfeiffer.
Kogut, B., Zander, U., 1996. What firms do? Coordination, identity, and learning. Organization Science 7 (5).

Lei, D., Hitt, M.A., et al., 1996. Dynamic core competences through meta-learning and strategic context. Journal of Management 22, 549-569.

Leiblein, M.J., Reuer, J.J., et al., 2002. Do make or buy decisions matter? The influence of organizational governance on technological performance. Strategic Management Journal 23, 817-833.

Leonard-Barton, D., 1992. Core capabilities and core rigidities: a paradox in managing new product development. Strategic Management Journal 13, 111-125.

Levy, D.T., 1985. The transactions cost approach to vertical integration: an empirica examination. Review of Economics and Statistics 67, 438-445.

Macher, J.T., 2006. Technological development and the boundaries of the firm: a knowledge-based examination in semiconductor manufacturing. Management Science 52 (6), 826-843.

Mayer, K.J., Nickerson, J.A., 2005. Antecedents and performance implications of contracting for knowledge workers: evidence from information technology services. Organization Science 16 (3), 225-242.

Mayer, K.J., Salomon, R.M., 2006. Capabilities, contractual hazard, and Governance: integrating resource-based and transaction cost perspectives. Academy of Management Journal 49, 942-959.

Monteverde, K., 1995. Technical dialog as an incentive for vertical integration in the semiconductor industry. Management Science 41, 1624-1638.

Nelson, R.R., Winter, S.G., 1982. An Evolutionary Theory of Economic Change. Harvard Business School Press, Cambridge, MA.

Nickerson, J.A., Zenger, T.R., 2004. A knowledge-based theory of the firm - the problem-solving perspective. Organization Science 15 (6), 617.

Panzar, J.C., Willig, D., 1981. Economies of scope. American Economic Review 71 (2), 268.

Pisano, G., 1990. The R\&D boundaries of the firm: an empirical analysis. Administrative Science Quarterly 35, 153-176.

Powell, W.W., Koput, K.W., et al., 1996. Interorganizational collaboration and the locus of innovation: networks of learning in biotechnology. Administrative Science Quarterly 41, 116-145.

Raudenbush, S.W., Bryk, A.S., 2001. Hierarchical Linear Models: Applications and Data Analysis Methods, 2nd edition. Sage Publications, Inc.

Ro, Y.K., Liker, J.K., et al., 2007. Modularity as a strategy for supply chain coordination: the case of U.S. auto. IEEE Transactions on Engineering Management 54 (1), $172-189$.

Rothaermel, F.T., Deeds, D., 2004. Exploration and exploitation alliance in biotechnology: a system of new product development. Strategic Management Journa 25 (3), 201-221.

Rothaermel, F.T., Hitt, M.A., et al., 2006. Balancing vertical integration and strategic outsourcing: effects on product portfolio, product success, and firm performance. Strategic Management Journal 27, 1033-1056.

Sanchez, R., Mahoney, J.T., 1996. Modularity, flexibility, and knowledge management in product and organization design. Strategic Management Journal 17 (winter special issue), 63-76.

Shibata, T., Yano, M., et al., 2005. Empirical analysis of evolution of product architecture fanuc numerical controllers from 1962 to 1997. Research Policy 34 $13-31$.

Sturgeon, T., 2002. Modular production networks: a new American model of industrial organization. Industrial and Corporate Change 11 (3), 451-496.

Takeishi, A., 2002. Knowledge partitioning in the interfirm division of labor: the case of automotive product development. Organization Science 13, 321-338.

Ulrich, K., 1995. The role of product architecture in the manufacturing firm. Research Policy 24, 419-440.

Wernerfelt, B., 1984. A resource-based view of the firm. Strategic Management Journal $5,171-180$

Williamson, O.E., 1985. The Economic Institutions of Capitalism: Firms, Markets, Relational Contracting. Free Press, New York. 